\title{
Article \\ Short-Time/-Angle Spectral Analysis for Vibration Monitoring of Bearing Failures under Variable Speed
}

\author{
Edgar F. Sierra-Alonso ${ }^{1, *} \oplus$, Julian Caicedo-Acosta ${ }^{1,2} \oplus$, Álvaro Ángel Orozco Gutiérrez ${ }^{3}$, Héctor F. Quintero ${ }^{3}(\mathbb{C}$ \\ and German Castellanos-Dominguez ${ }^{1}$ (i) \\ 1 Signal Processing and Recognition Group, Universidad Nacional de Colombia, Manizales 170001, Colombia; \\ juccaicedoac@unal.edu.co (J.C.-A.); cgcastellanosd@unal.edu.co (G.C.-D.) \\ 2 SEDMATEC, Corporación Universitaria Autónoma de Nariño, Pasto 520002, Colombia \\ 3 Grupo de Investigación en AUTOMÁTICA, Universidad Tecnológica de Pereira, Pereira 660003, Colombia; \\ aaog@utp.edu.co (Á.Á.O.G.); hquinte@utp.edu.co (H.F.Q.) \\ * Correspondence: efsierraa@unal.edu.co
}

check for

updates

Citation: Sierra-Alonso, E.F.;

Caicedo-Acosta, J.; Orozco Gutiérrez,

Á.Á.; Quintero, H.F.;

Castellanos-Dominguez, G

Short-Time/-Angle Spectral Analysis for Vibration Monitoring of Bearing Failures under Variable Speed. Appl. Sci. 2021, 11, 3369. https://doi.org/ 10.3390/app11083369

Academic Editor: Oscar Duque-Perez

Received: 17 February 2021

Accepted: 17 March 2021

Published: 9 April 2021

Publisher's Note: MDPI stays neutral with regard to jurisdictional claims in published maps and institutional affiliations.

Copyright: (c) 2021 by the authors. Licensee MDPI, Basel, Switzerland. This article is an open access article distributed under the terms and conditions of the Creative Commons Attribution (CC BY) license (https:// creativecommons.org/licenses/by/ $4.0 /)$.

\begin{abstract}
Vibration-condition monitoring aims to detect bearing damages of rotating machinery's incipient failures mainly through time-frequency methods because of their efficient analysis of nonstationary signals. However, by having failures with impulse behavior, short-term events have a tendency to be diluted under variable-speed conditions, while information on frequency changes tends to be lost. Here, we introduce an approach to highlighting bearing impulsive failures by measuring short-term spectral components to deal with variable-speed vibrations. The short-term estimator employs two sliding windows: a small one that measures the instantaneous amplitude level and tracks impulsive components and a large interval that evaluates the average background amplitude. Aiming to characterize cyclo-non-stationary processes with impulsive behavior, the emphasizing high-order-based estimator based on the principle of spectral entropy is introduced. For evaluation, both visual inspection and classifier performance are assessed, contrasting the spectralentropy estimator with the widely used spectral-kurtosis approach for dealing with impulsive signals. The validation of short-time/-angle spectral analysis performed on three datasets at variable speed showed that the proposed spectral-entropy estimator is a promising indicator for emphasizing bearing failures with impulse behavior.
\end{abstract}

Keywords: spectral kurtosis; spectral entropy; bearing failure; vibration monitoring

\section{Introduction}

The adequate condition monitoring of bearing vibrations enables the reliable operation of mechanical equipment under complex working situations. To this end, health-condition monitoring assesses the development of internal fluctuating vibration amplitudes generated by bearing failures that deteriorate rotating machinery [1]. Vibration monitoring is widely employed to detect bearing damage of incipient failures in gas, steam, and wind turbines [2-4], and electric vehicles [5]. In domain-based vibration monitoring, signalprocessing methods that effectively synchronously obtain information from time and frequency domains are preferred to deal with nonstationary data. Among time-frequency methods, the following are the most prominent: Empirical mode decomposition that has some limitations, such as border effect evidence, unreliable stopping criterion, and low spectral resolution (separating closely spaced spectral components) because of mode mixing [6]; wavelet transforms that have an energy-leakage issue for which mother wavelet selection must be appropriate because the contents of the daughter wavelets need to be closely matched with each considered signal [7]; short-time Fourier transform (STFT), with the constraint of nonreachable simultaneous best time and frequency resolution [8]. However, the STFT method is widely adopted in preprocessing nonstationary vibration signals to discard redundant information and present more powerful fault characteristics [9]. 
To date, several moment-based values were reported to measure the damage degree of rotating machinery to fault spectrum sparsity or envelope spectra exhibiting discrete peaks at corresponding fault frequencies. In particular, kurtosis (also related to $\ell_{1} / \ell_{2}$ norms [10]) measures the spikiness of a vibration signal [11], better estimating the resonance frequency band of bearing impulsive failures $[12,13]$. However, kurtosis is sensitive to impulsive noise structure, so that it tends to decrease in value when the frequency of the impulses increases or impulses overlap [14]. Sparse filtering with generalized $\ell_{p} / \ell_{q}$ norms [15] was also employed with more flexible ruling parameters ( $p$ and $q)$ to characterize bearing faults [16]. However, a large value of $p$ measures sensitivity to outliers, while a small $p$ makes the measure ineffective in sensing sparsity [17]. Entropy is another useful tool in detecting the dynamic characteristics of nonlinear vibration signals, providing robustness to noise and adequate cluster ability, independent of prior knowledge [18]. Estimation types commonly used in fault diagnosis include approximate energy entropy and sample entropy [19], which may be dependent on intrinsic parameters and have limited ability to capture longterm correlations. To cope with this issue, a multiscale approach is proposed that shortens the time series at higher scales, which results in higher fluctuations of entropy values at scale factors [20]. Permutation entropy can also be applied in the analysis of vibration signals [21]. However, entropy methods tend to exclude high-frequency information, yielding limited diagnostic performance in identifying bearing health states [22].

Generally, the STFT approach depends on the length of the applied window and its shape. In this regard, bearing-fault analysis uses a rectangular window with a fixed length with the limitation of power leakage and insensitive tracking of impact signal components [23]. This difficulty mainly concerns the event identification of highly localized time samples. To cope with this issue, the sliding SFFT approach of bearing-fault waveforms is often computed (sliding entropy [24] or sliding kurtosis [25]). Although the sliding strategy enhances the time resolution of measures, it may compromise the quality of probability function estimation due to fewer data being available within the working window [26].

Here, we introduce an approach to highlighting impulsive bearing failures. After mapping the vibration signal into the angular domain, we propose filtering with an angle-varying transfer function to magnify failures' impulsive behavior when dealing with variable-speed records. Namely, we measured short-term spectral components by operating two sliding windows: a small one that measures the instantaneous amplitude level and tracks impulsive components, and a large interval that evaluates average background amplitude. Aiming to characterize cyclo-non-stationary processes with impulsive behavior, the emphasizing high-order-based estimator based on the principle of spectral entropy is introduced. For evaluation purposes, both visual inspection and classifier performance were assessed, contrasting the spectral-entropy estimator with the widely used spectralkurtosis approach for dealing with impulsive signals. The validation of short-time/-angle spectral analysis, performed on three datasets at variable speed, showed that the proposed spectral-entropy estimator is a promising indicator for emphasizing bearing failures with impulse behavior.

The rest of the paper is organized as follows: Section 2 briefly discusses squaredenvelope-spectrum estimation and emphasizing impulsive components; Section 3 describes the experiment setup and the simulation framework of rolling-element bearing faults to test the methodology at instantaneous angular speed; Section 4 discusses the validation results performed by three vibration signal collections. Lastly, Section 5 outlines the main conclusions of the paper. 


\section{Methods}

\subsection{Estimation of Squared Envelope Spectrum}

In practice, vibration-signal analysis is performed on envelope spectrum $\tilde{x} \in \mathbb{R}^{K}$, which is the absolute average over $L$ periodograms, as follows:

$$
\tilde{\boldsymbol{X}}[k]=\frac{1}{L \epsilon_{w}} \sum_{l=0}^{L-1}\left|\underset{n \rightarrow k}{\mathcal{F}}\left\{|\hat{\boldsymbol{X}}[l, n]|^{2}\right\}\right|^{2}
$$

where $\mathcal{F}_{n \rightarrow k}\{\cdot\}$ stands for Fourier transform, and $\hat{X} \in \mathbb{C}^{L \times N}$ is the analytical signal of $X \in \mathbb{R}^{L \times N}$ used to calculate the square envelope of the filtered vibration signal, as follows:

$$
\boldsymbol{X}[l, n]=\underset{k \rightarrow n}{\mathcal{F}^{-1}}\left\{S_{X}[l, k] \boldsymbol{\Xi}[l, k]\right\}
$$

where $\Xi \in \mathbb{C}^{L \times K}$ is a filter mask that emphasizes the impulsive components generated by rolling-element bearing failures, and matrix $S_{X} \in \mathbb{C}^{L \times K}$ holds the short-time Fourier transform (STFT) of a vibration signal computed over sliding window $\boldsymbol{w}_{\tau}$, defined as below:

$$
S_{X}[l, k]:=\sum_{n=0}^{N-1} x[n] \boldsymbol{w}_{\tau}[n-l] \exp (-j 2 \pi n k), l \in L
$$

where $x \in \mathbb{R}^{N}, x \subseteq X$, is a cyclo-non-stationarity signal spanned over the domain of observation (either time or angular) that is sampled as $x[n]:=x\left(n / f_{s}\right)$, at sampling frequency $f_{s}, \boldsymbol{w}_{\tau}[n]$ is window of length $\tau$ used to implement short-term analysis, and $\epsilon_{w}=$ $\sum_{n \in N}\left|\boldsymbol{w}_{\tau}[n]\right|^{2}$ is the real-value energy of $\boldsymbol{w}_{\tau}$.

\subsection{Spectral Filter Emphasizing Impulsive Components}

For characterizing cyclo-non-stationary processes, different approaches to filter modeling can be used to highlight the presence of impulsive components in envelope spectrum $\tilde{X}$, including the following moment-based estimators:

- Spectral kurtosis (SK): provided there is a cyclostationary process, the highlighting filter (noted as $\xi_{1} \in \mathbb{R}^{K}$ ) is modeled through kurtosis, having elements defined by the following absolute value moment [27]:

$$
\xi_{1}[k]=\frac{\left\langle\left|S_{X}[l, k]\right|^{4}\right\rangle_{l}}{\left\langle\left|S_{X}[l, k]\right|^{2}\right\rangle_{l}^{2}}-2, k \in K, \xi_{1} \subseteq \Xi
$$

where $\left\langle\mid \cdot{ }^{n}\right\rangle_{1}$ stands for the empirical moment of the $n$-th order, averaging representation $S_{X}$ over $l$ domain.

- $\quad$ Spectral entropy (SE): an entropy-based filter (noted as $\xi_{2} \in \mathbb{R}^{K}$ ) is proposed that is modeled as follows:

$$
\xi_{2}[k]=\mathbb{H}\left\{S_{X}[l, k]: \forall l \in L\right\}, \xi_{2} \subseteq \Xi,
$$

where $\mathbb{H}\{\cdot\}$ is the VQ entropy proposed in [28].

To deal with the nonstationarity of vibration signals, the moment-based estimator can be performed within a wider window of spectral matrix $S_{X}$, as below:

$$
\Xi[l, k]=\xi_{i}\left\{x_{M}[n+l]\right\}[k], \quad i=1,2,
$$

where $x_{M}[n]=[x[n], \cdots, x[n+M-1]]$ is a subvector of size $M<N$ extracted from $x$. In the following, when sliding filter $\Xi[l, k]$, is denoted as sliding spectral kurtosis (SSK) if computed by $\xi_{1}\{\cdot\}$. Otherwise, the sliding filter is denoted as sliding spectral entropy (SSE) if computed by $\xi_{2}\{\cdot\}$. 


\section{Experiment Setup}

For evaluation purposes, a visual inspection of the proposed filtering methodology was initially performed for inner race faults at variable speed, employing a simulated envelope spectrum computed from the tested vibration signal. As outlined in Figure 1, after completing the shared procedures of segmentation and spectrogram estimation, we also assessed the proposed filtering approach's influence by appraising the classification accuracy of failures in parallel with testing both filtering approaches for impulsive components: spectral kurtosis and spectral entropy. Thus, the validation of the proposed filtering methodology was achieved in three real-world vibration-signal collections (the tailored software to support the validating pipeline of the proposed short-time/-angle spectral analysis is now publicly available at https:/ / github.com/juccaicedoac03/tf-Comp-ex_vib): (1) The SAFRAN dataset, which holds a challenging record of aircraft engines dealing with variable speed in a run-up test. (2) the Case Western Reserve University (CWRU) dataset, which consists of 59 records from two damaged bearings at constant speed; and (3) the Universidad Nacional de Colombia (UNC) dataset, which holds 42 variable-speed signals, including a concrete set of testing bearing failures.

For the above datasets, each vibration signal was mapped into the angular domain to remove the shaft speed's influence before validating the filtering approaches, the baseline versions (SK and SE) and their proposed sliding versions (SSK and SSE). We also fixed the set parameter as shown in Table 1, namely, the sliding STFT window $\boldsymbol{w}_{\tau}$ to compute SK and SE (as suggested in [29]), and length $M$ of the segment $x_{M}$ to calculate SSE and SSK. To feed the classifier, the single-trial feature vectors extracted from SK and SE are: $\xi_{1}[k]$, and $\xi_{2}[k]$ (see Equations (4) and (5)). To deal with the poor time alignment of time-frequency sets $\Xi[l, k]$, the mean and standard deviation (STD) through time index $l$ were extracted as a feature from SSK and SSE. The classification procedure was implemented using Python library Scikit-learn, and the following working parameters were selected. The initial featureselection step employed a support vector machine with $C=0.1$ (selecting features with nonzero coefficients and stochastic gradient descent optimization), and cross-validation was carried out through a leave-one-out scheme handling 100 trials.

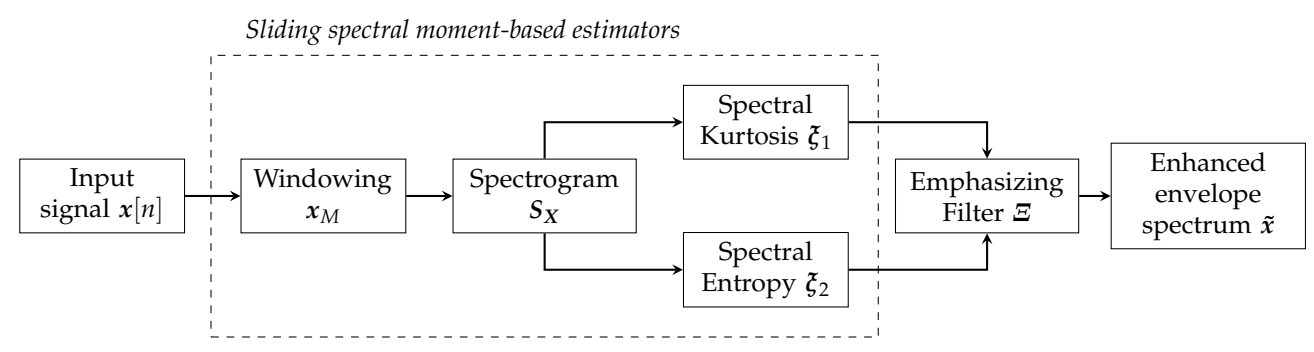

Figure 1. Validating pipeline of proposed short-time/-angle spectral analysis for vibration monitoring.

Table 1. Testing dataset parameters: $\boldsymbol{w}_{\tau}$, sliding short-time Fourier transform (STFT) window; $M$, length segment for computation of either sliding spectral entropy (SSE) or sliding spectral kurtosis (SSK) estimator. All parameters measured in samples.

\begin{tabular}{ccccc}
\hline Parameter & Simulation & SAFRAN & CWRU & UNC \\
\hline$w_{\tau}$ & 256 & 256 & 256 & 256 \\
$M$ & 2048 & 4096 & 8192 & 32,768 \\
Samples per revolution & 128 & 256 & 400.67 & 1024 \\
\hline
\end{tabular}

\section{Simulation Framework of Rolling-Element Bearing Faults}

To reproduce records with constant instantaneous angular speed (IAS) to be tested, we initially created a fault record with a rolling-element bearing (REB) using a superposition of periodic impulses at the fault frequency (i.e., the average time between impacts) using the model suggested in [30]: 


$$
x[n]=\sum_{i \in I} a_{i} s\left[n-i T-\tau_{i}\right]+\eta[n],
$$

where $\left\{a_{i}\right\}_{i=1}^{I}$ is the set of real-value amplitudes, $\{\eta[n]\}_{n \in \mathbb{N}}$ is additive white Gaussian noise, $s[n]$ is a function that models an impact over time domain $n$, and $\left\{\tau_{i}\right\}$ is a random variable that adds small variations within fault-frequency period $T$, which remained constant between impacts.

Table 2 presents the REB faults modeled by a frequency that depends on REB geometry, including contact angle, pitch diameter, and ball diameter. The top row of Figure 2 presents an REB failure in the ball-pass frequency inner race (BPFI), modeled by impulse function $s[n]=\sin (2 \pi 5000 t) \exp (-0.22 \pi 5000 t)$, having a resonance frequency of $5 \mathrm{kHz}$ and a fault frequency of 5.875 times the rotational speed fixed at $50 \mathrm{~Hz}$. Figure $2 \mathrm{a}, \mathrm{b}$ display an example of clean and noisy records, respectively, showing that the resonance band was at $5 \mathrm{kHz}$ on both representations of power spectral density (PSD; marked in orange). However, the failure is not visible on either spectrogram.

Table 2. Adjusted frequencies of rolling-element-bearing (REB) failures. Note: $f_{r}$, instantaneous angular speed (IAS); $d$, REB diameter; $D$, pitch circle diameter; $N$, number of REBs; and $\Phi$, contact angle.

\begin{tabular}{lc}
\hline Failure & Model \\
\hline Ball-pass frequency inner race (BPFI) & $N f_{r}\left(1+\frac{d}{D} \cos \Phi\right) / 2$ \\
Ball-pass frequency outer race (BPFO) & $N f_{r}\left(1-\frac{d}{D} \cos \Phi\right) / 2$ \\
Fundamental train frequency (FTF) & $f_{r}\left(1-\frac{d}{D} \cos \Phi\right) / 2$ \\
Ball spin frequency (BSF) & $D f_{r}\left(1-\left(\frac{d}{D} \cos \Phi\right)^{2}\right) / d$ \\
\hline
\end{tabular}

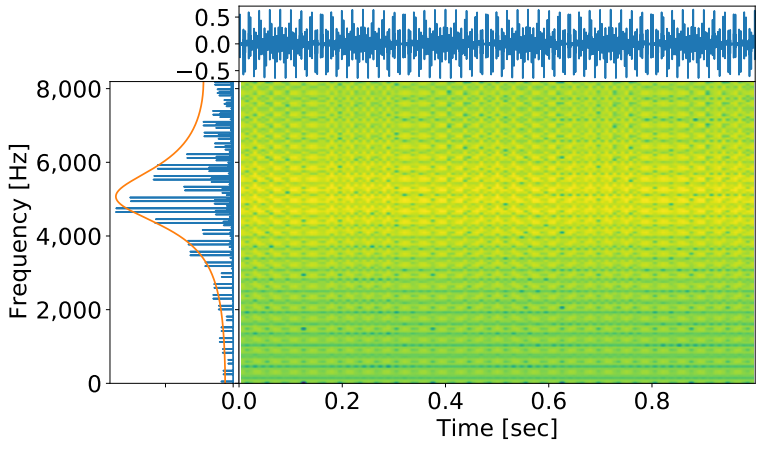

(a)

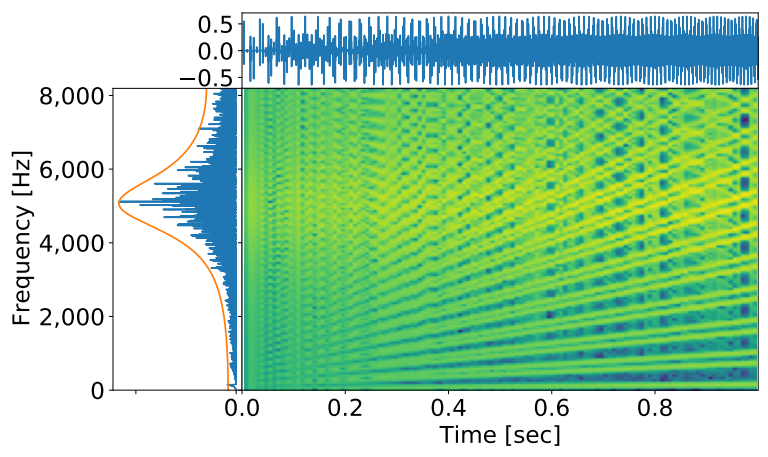

(c)

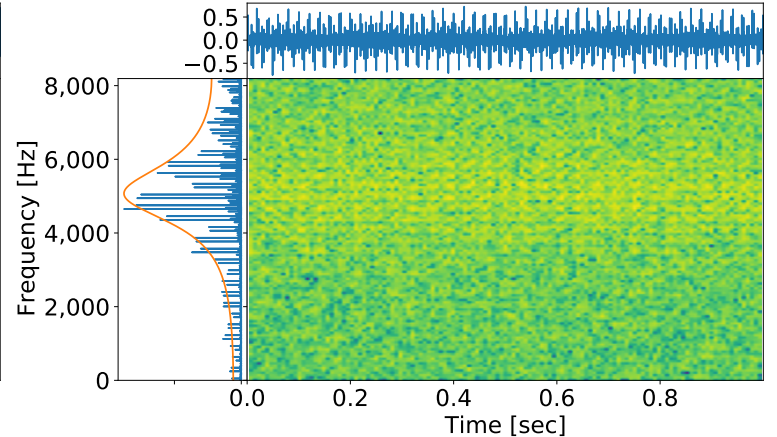

(b)

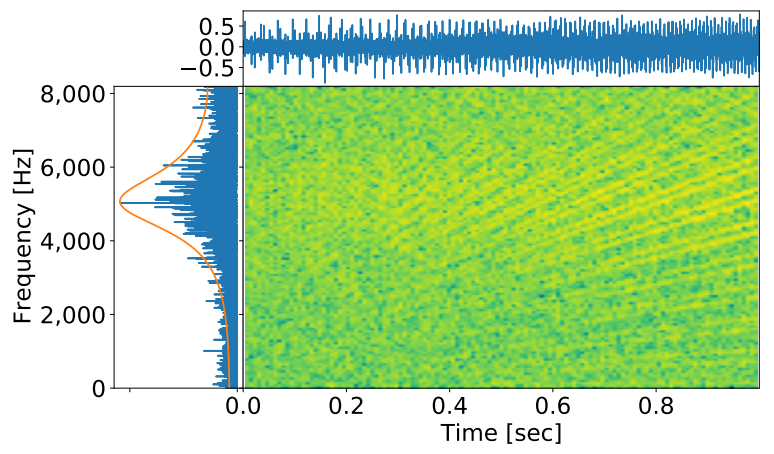

(d)

Figure 2. Modeling of REB failures. Figures in top row $(\mathbf{a}, \mathbf{b})$ show the spectrograms estimated for constant IAS and the figures bottom row (c,d) show the spectrogram of time-varying IAS. Left-hand side, corresponding plots of the clean signal; right-hand side, signal perturbed by noise at $3 \mathrm{~dB}$. 
To simulate a record that presents time-varying IAS, an additional function $\phi[n]$ was introduced to rule the time-varying fault period, resulting in the following framework to model an REB angle-varying failure signal:

$$
y[n]=\sum_{i \in I} a_{i} s\left[\phi[n]-i T-\tau_{i}\right]+\eta[n],
$$

With the aim of removing the influence of variable speed on failure detection, the ruling function must fulfil composition operation $n=\phi[n] \circ \phi_{1}^{-1}[n]$, such that the uniform angular resampling holds (or computed order tracking): $y\left[\phi^{-1}[n]\right]=y_{\gamma}[n]$, where $y_{\gamma}[n]$ is a version of $y[n]$ with unitary speed, and $\gamma$ represents the angular domain.

The bottom row in Figure 2 shows an example of simulated REB failure with variable speed, linearly increasing from 25 to $150 \mathrm{~Hz}$. Thus, the period between impulses becomes time-varying, but impulse function's resonance frequency $s[n]$ remains at $5 \mathrm{kHz}$. Transforming the signal into the angular domain removes the influence of speed, yielding a vibration signal at a constant speed of $1 \mathrm{~Hz}$.

The use of impulse-based models in Equations (7) and (8) led to spectral representation with an extended frequency content. Instead, failure analysis was performed on the fluctuating spectral magnitude (i.e., envelope spectrum). However, the impulsive signal behavior had to be filtered to remove spurious components such as IAS harmonics to extract the envelope spectrum. In practice, envelope-spectrum analysis for fault detection is presented through visual examination in the absence of its standard scoring.

Lastly, Figure 3 displays envelope spectra computed for the evaluating scenarios. As seen in Figure 3a, even though the first SK harmonic is the most powerful, some higher fault harmonics vanished (marked with dashed red lines), especially the third. Instead, Figure $3 \mathrm{~b}-\mathrm{d}$ show that the spectral content of SE, SSK, and SSE smoothly faded, providing a better visual interpretation of failures.

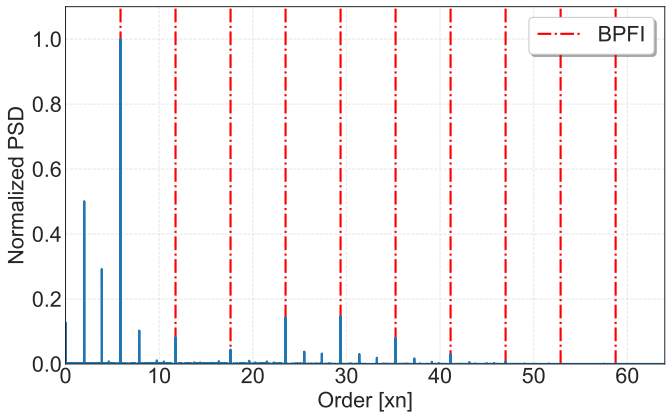

(a) SK

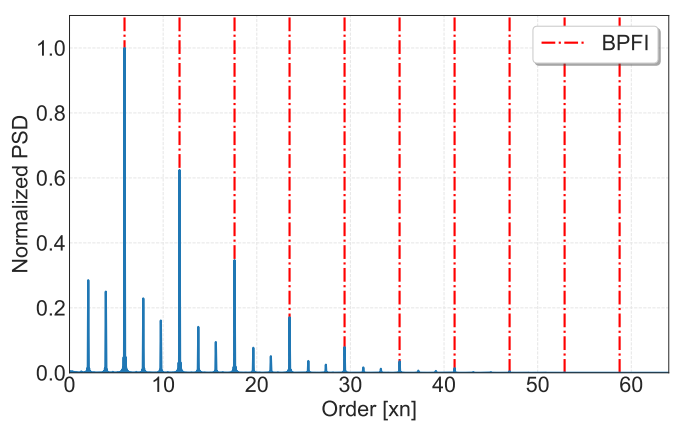

(c) SSK

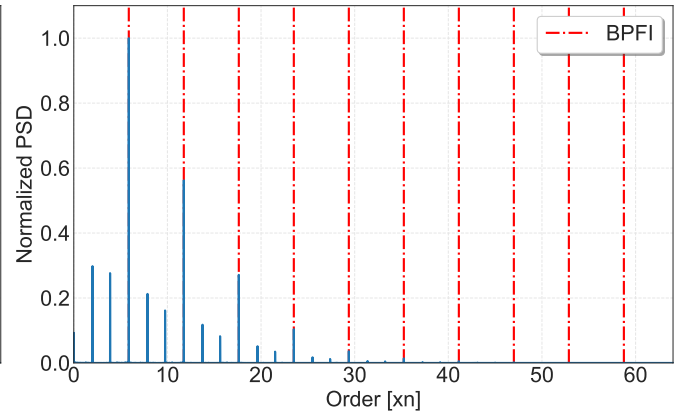

(b) SE

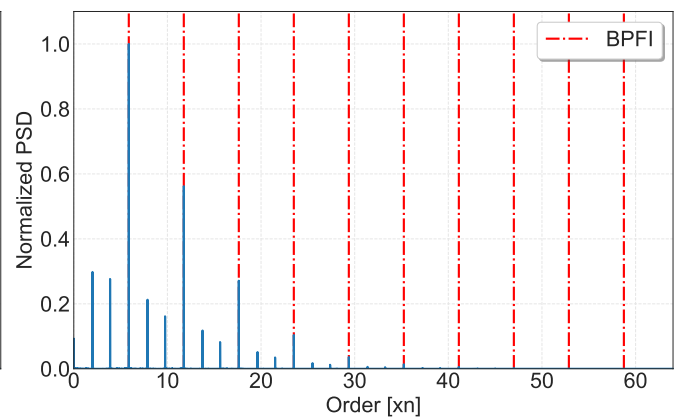

(d) SSE

Figure 3. Examples of envelope spectra (obtained from power spectral density (PSD)) performed by simulated signal. Top row, spectral-kurtosis (SK) and spectral-entropy (SE) estimators; bottom row, their sliding versions (sliding spectral kurtosis (SSK); sliding spectral entropy (SSE)). Order represents shaft-speed harmonics. 


\section{Results and Discussion}

\subsection{Experiment Results by SAFRAN}

Data were acquired from a ground test using experimental hardware that included a civil aircraft engine with damaged bearings and sensor locations. The general overview of the tested engine and its accessory gearbox is given in [31], where shafts L1-L5 are labeled. The engine had two main shafts and an accessory gearbox with equipment such as pumps, filters, alternators, and a starter. The accessory gearbox was linked to the high-pressure shaft HP by a radial drive shaft and a horizontal drive shaft. The database holds the healthy-state record (labeled as ACC1) and bearing-failure record (ACC2); both signals had a sampling frequency of $50 \mathrm{kHz}$. The tachometer signal is also provided. Due to ACC2 data being acquired closer to the L5 location, the outer race fault was expected to be more influential on this shaft than that in L1 (placed more distantly). Table 3 presents the fault frequencies of the bearing gearbox, referenced to L5, as detailed in [31].

Table 3. Fault bearing frequencies of supporting shafts L1, L4, L5, with speed of L5 as reference.

\begin{tabular}{lccc}
\hline & L1 (L5) & L4 (L5) & L5 (L5) \\
\hline Speed & 1.34 & 0.984 & 1 \\
\hline FTF & 0.55 & 0.40 & 0.43 \\
BSF & 3.46 & 2.44 & 3.56 \\
BPFI & 7.95 & 5.87 & 10.24 \\
BPFO & 5.45 & 3.97 & 7.76 \\
\hline
\end{tabular}

Figure 4 displays the spectrogram of the bearing-failure record estimated within the entire frequency range $[0,25] \mathrm{kHz}$ (see left plot), indicating that the IAS signal had the highest energy arising at the 62nd harmonic. For illustration, the left plot shows the spectrogram of the downsampled version of ACC2 (by 16 times) within $[0,1.56] \mathrm{kHz}$ (right plot), for which IAS had a low signal-to-noise (SNR) ratio, having the highest energy of the third harmonic but hiding other harmonics.
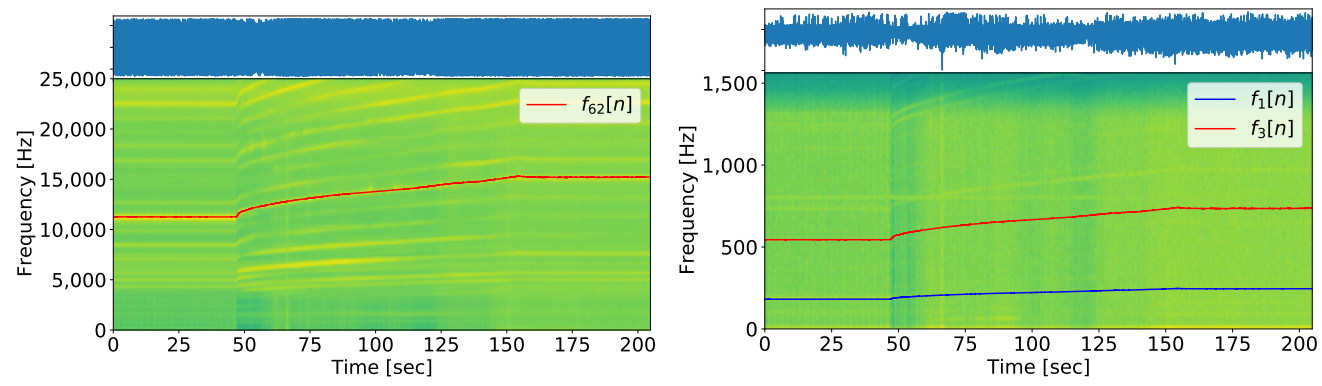

Figure 4. Spectrograms of ACC2 record estimated within full frequency range of $[0,25] \mathrm{kHz}(\mathbf{l e f t})$, and for downsampled version (by 16 times) within $[0,1.56] \mathrm{kHz}$ (right).

Figure 5 depicts the resulting envelope spectra of the considered filtering scenarios, showing that the SK approach had a sharp peak at failure frequency (see Figure 5a), but harmonics became less visible. In the case of SE, failure frequency was missed (first harmonic), and the third harmonic was then instead clearly observed (see Figure 5b). Regarding SSK (Figure 5c) and SSE (Figure 5d), either short-term approach displayed the envelope spectrum more accurately with a dominant presence of the fault frequency and all its harmonics. Hence, the short-term filtering approach improved failure diagnosis in the angular domain. 


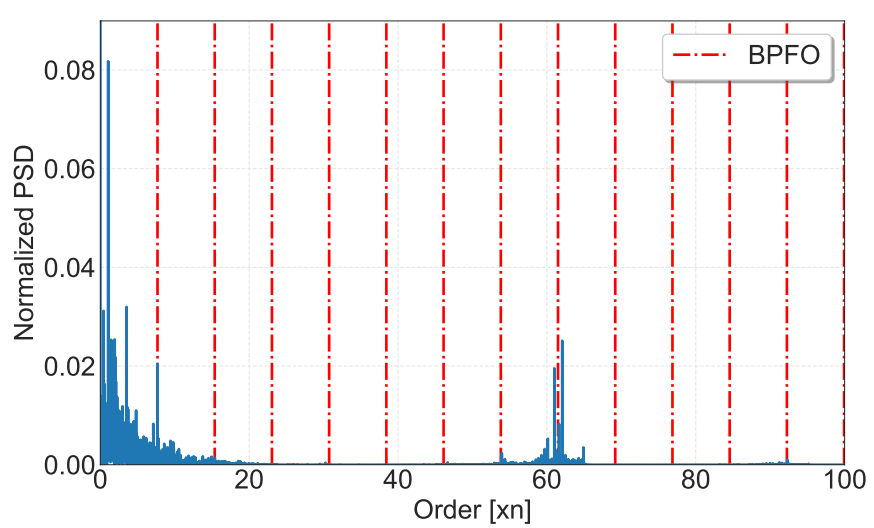

(a) SK

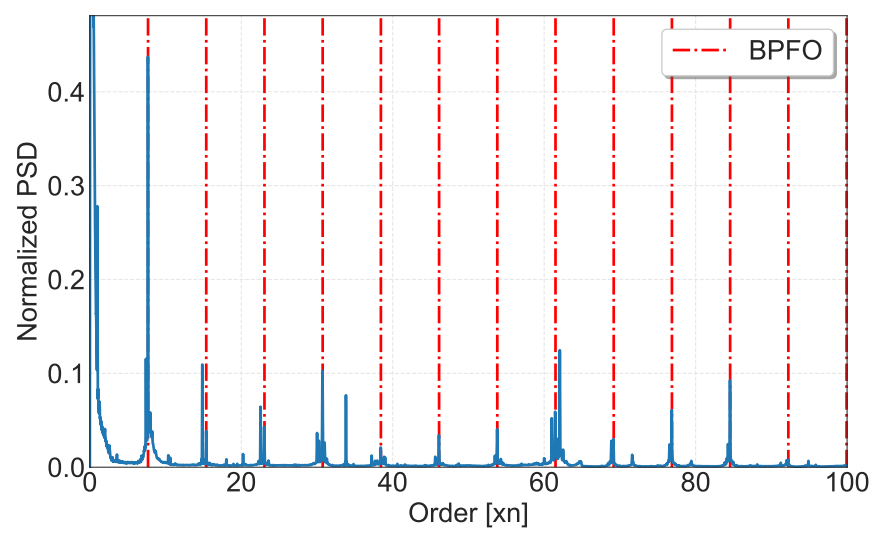

(c) SSK

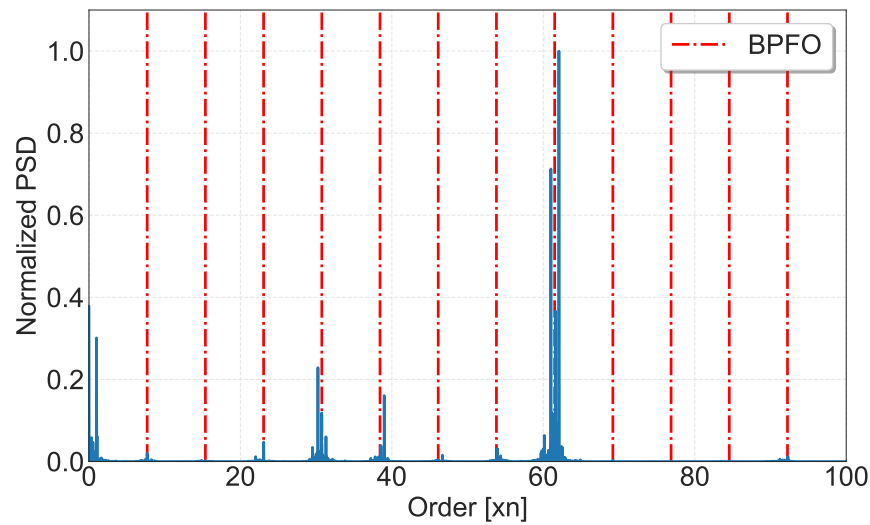

(b) SE

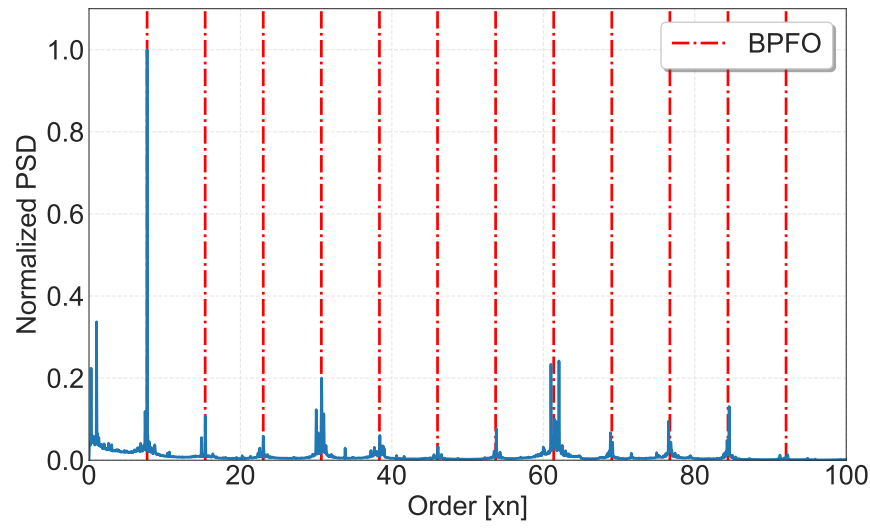

(d) SSE

Figure 5. Examples of envelope spectra (obtained from PSD) from aircraft-engine data (SAFRAN). Top row, SK and SE estimators; bottom row, their sliding versions (SSK; SSE).Order represents harmonics of shaft speed.

\subsection{Experiment Results from CWRU}

Figure 6 shows the test rig used for signal acquisition consisting of a $2 \mathrm{HP}$ electric motor, driving a shaft on which a torque-transducer encoder was mounted. Torque was applied to the shaft via a dynamometer and an electronic control system. During testing, faults ranging in diameter from 0.18 to $0.71 \mathrm{~mm}$ were seeded onto the motor's drive- and fan-end bearings using electrodischarge machining (EDM). Faults were seeded on rolling elements, and inner and outer races. Each faulty bearing was separately reinstalled on the test rig, which was then run at a constant speed for motor loads of $0-3$ horsepower (approximate motor speeds of 1797-1720 rpm). Table 4 shows the relevant bearing details and fault frequencies. During each test, acceleration was measured in the vertical direction on the drive-end bearing housing (DE). In some cases, acceleration was also acquired in the fan-end bearing housing (FE) vertical direction and the motor supporting base plate (BA). Used sample rates were $12 \mathrm{kHz}$ for some tests and $48 \mathrm{kHz}$ for others. Further details regarding the test setup can be found in the CWRU Bearing Data Center website at https:/ / csegroups.case.edu/bearingdatacenter/pages/welcome-case-western-reserveuniversity-bearing-data-center-website. 
Table 4. Bearing fault frequencies for the test rig.

\begin{tabular}{lllccc}
\hline \multirow{2}{*}{ Rig Position } & \multirow{2}{*}{ Model Number } & \multicolumn{4}{c}{ Fault Frequencies (IAS Multiple) } \\
\cline { 3 - 5 } & & BPFI & BPFO & FTF & BSF \\
\hline Drive end & SKF 6205-2RS JEM & 5.415 & 3.585 & 0.3983 & 2.357 \\
Fan end & SKF 6203-2RS JEM & 4.947 & 3.053 & 0.3816 & 1.994 \\
\hline
\end{tabular}

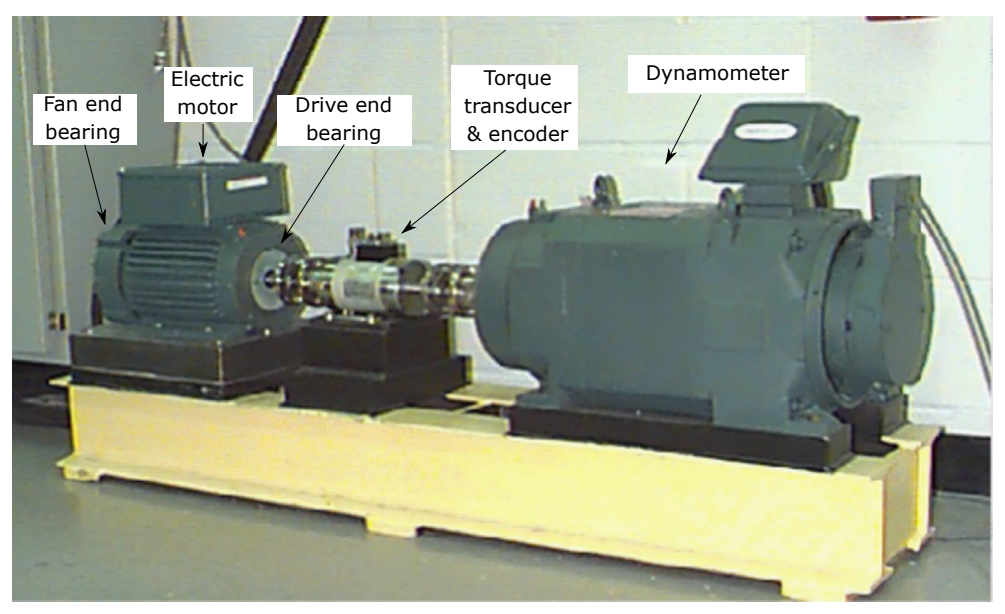

Figure 6. Case Western Reserve University test rig.

The CWRU dataset holds a benchmark in bearing-failure identification comprising the following steps [32]:

1. Discrete or random separation (DRS) to remove deterministic (discrete frequency) components.

2. Spectral kurtosis to determine the most impulsive band, followed by bandpass filtering.

3. Envelope analysis (squared envelope spectrum) of a bandpass-filtered signal.

Since this benchmark contains the SK procedure within the bearing fault detection framework, it was well-suited for comparison with the proposed approach that we perform using 59 data records labeled as "nondiagnosable" as described in Table 5.

Table 5. Categorization labels assigned to diagnosis states.

\begin{tabular}{cll}
\hline $\begin{array}{c}\text { Diagnosis } \\
\text { Category }\end{array}$ & $\begin{array}{l}\text { Diagnosis } \\
\text { Success }\end{array}$ & Explanation \\
\hline Y1 & Yes & $\begin{array}{l}\text { Data clearly diagnosable and show classical characteristics } \\
\text { for a given bearing fault in both t-f domains } \\
\text { Data clearly diagnosable with nonclassical characteristics } \\
\text { in either or both t-f domains } \\
\text { Data probably diagnosable; e.g., envelope spectrum } \\
\text { shows discrete components at expected fault frequencies, } \\
\text { but not dominant in the spectrum } \\
\text { Data potentially diagnosable; e.g., envelope spectrum shows } \\
\text { smeared components that appear to coincide with expected fault } \\
\text { frequencies } \\
\text { Data not diagnosable for specified bearing fault, but with } \\
\text { other identifiable problems (e.g., looseness) } \\
\text { Data not diagnosable and virtually indistinguishable from noise, } \\
\text { excepting possibly shaft harmonics in the envelope spectrum }\end{array}$ \\
N1 & Partial & No
\end{tabular}

In terms of interpretation, the visual inspection of estimated envelope spectra allowed for newly categorizing 7 records after SSK, 27 records after SE, and 25 records of SSE 
as shown in Table 6. Thus, SE presented the best results followed by SSE. However, there was no substantial evidence of improvement after using SSK due to it being an approach designed to deal with time-varying IAS. The CWRU dataset was at constant speed. Entropy-based spectral filtering improves the SK method, meaning that entropy allows for highlighting impulsive components from complex data such as ball failure, yielding significant enhancement.

Table 6. Categorization of nondiagnosable records in [32] using SSK (normal font), SE (italic), SSE (bold). Each sampled record has three simultaneous measurements DE/FE/BA. Diagnosable records per approach: 7 partially diagnosable (SSK), 1 diagnosable and 26 partially diagnosable (SE), 25 Partially diagnosable records (SSE).

\begin{tabular}{|c|c|c|c|c|c|}
\hline & \multicolumn{5}{|l|}{ Fault Type } \\
\hline & IR & Ball & OR Centered & OR Orthogonal & OR Opposite \\
\hline $\begin{array}{l}\text { Drive end } \\
\text { bearing faults } \\
12 \mathrm{kHz} \text { data }\end{array}$ & $\begin{array}{l}3001=\mathrm{N} 2 /-/-, \\
3002=\mathrm{N} 2 /-/-, \\
3003=\mathrm{N} 2 /-/-, \\
3004=\mathrm{N} 2 /-/-, \\
3001=P 2 /-/-, \\
3002=P 2 /-/-, \\
3003=P 2 /-/-, \\
3004=P 2 /-/-, \\
3001=\mathrm{P} 2 /-/-, \\
3002=\mathrm{P} 2 /-/-, \\
3003=\mathrm{P} 2 /-/-, \\
3004=\mathrm{P} 2 /-/-\end{array}$ & $\begin{array}{l}118=\mathrm{N} 2 / \mathrm{N} 2 / \mathrm{N} 2, \\
119=\mathrm{N} 2 / \mathrm{N} 2 / \mathrm{N} 2, \\
120 \mathrm{DE}=\mathrm{P} 1,120 \mathrm{BA}=\mathrm{N} 2, \\
121 \mathrm{BA}=\mathrm{P} 2,187 \mathrm{FE}=\mathrm{N} 2, \\
224 \mathrm{DE}=\mathrm{N} 1,224 \mathrm{BA}=\mathrm{P} 2, \\
225 \mathrm{DE}=\mathrm{P} 2,225 \mathrm{FE}=\mathrm{N} 2, \\
118=P 2 / \mathrm{N} 2 / \mathrm{N} 1 \\
119=P 1 / \mathrm{N} 2 / \mathrm{N} 1 \\
120 D E=P 2,120 B A=P 2, \\
121 B A=N 2,187 F E=N 1, \\
224 D E=P 2,224 B A=P 2, \\
225 D E=P 2,225 F E=N 1, \\
\mathbf{1 1 8}=\mathbf{P} 2 / \mathrm{N} 2 / \mathbf{N} 1, \\
\mathbf{1 1 9}=\mathbf{P} 2 / \mathbf{N} 2 / \mathbf{N} 1, \\
\mathbf{1 2 0 D E}=\mathbf{P} 1, \mathbf{1 2 0 B A}=\mathbf{P 2}, \\
\mathbf{1 2 1 B A}=\mathbf{N} 2, \mathbf{1 8 7 F E}=\mathbf{N} 1, \\
\mathbf{2 2 4 D E}=\mathbf{P} 1, \mathbf{2 2 4 B A}=\mathbf{N} 1, \\
\mathbf{2 2 5 D E}=\mathbf{P} 1, \mathbf{2 2 5 F E}=\mathbf{N} 1\end{array}$ & $\begin{array}{l}197 \mathrm{FE}=\mathrm{N} 2, \\
197 \mathrm{BA}=\mathrm{P} 2, \\
198 \mathrm{FE}=\mathrm{N} 2, \\
198 \mathrm{BA}=\mathrm{N} 1, \\
199 \mathrm{FE}=\mathrm{N} 2, \\
200=\mathrm{N} 2 / \mathrm{N} 2 / \mathrm{P} 2, \\
197 F E=N 1, \\
197 B A=Y 2, \\
198 F E=P 2, \\
198 B A=P 2, \\
199 F E=N 1, \\
200=P 1 / N 1 / P 2, \\
\text { 197FE = N2, } \\
\text { 197BA = P1, } \\
\text { 198FE = N2, } \\
\text { 198BA = P2, } \\
\text { 199FE = N2, } \\
\text { 200 = P2/N1/P2 }\end{array}$ & - & - \\
\hline $\begin{array}{l}\text { Drive end } \\
\text { bearing faults } \\
48 \mathrm{kHz} \text { data }\end{array}$ & $\begin{array}{l}174=\mathrm{N} 1 / \mathrm{N} 1 \\
174=\mathrm{N} 2 / \mathrm{N} 2 \\
\mathbf{1 7 4}=\mathbf{N} 2 / \mathbf{N} 2\end{array}$ & $\begin{array}{l}122=\mathrm{N} 2 / \mathrm{N} 2 \\
123=\mathrm{N} 2 / \mathrm{N} 2, \\
124=\mathrm{P} 2 / \mathrm{N} 2,125=\mathrm{P} 2 / \mathrm{N} 1, \\
192=\mathrm{N} 1 / \mathrm{N} 1,228 \mathrm{DE}=\mathrm{N} 2, \\
229 \mathrm{DE}=\mathrm{N} 2,122=P 1 / \mathrm{N} 2 \\
123=P 2 / \mathrm{N} 2,124=P 2 / \mathrm{N} 1 \\
125=P 1 / \mathrm{N} 1,192=P 2 / \mathrm{N} 1 \\
228 D E=\mathrm{N} 2,229 D E=\mathrm{N} 2 \\
\mathbf{1 2 2}=\mathbf{P} 2 / \mathbf{N} 1, \mathbf{1 2 3}=\mathbf{P} 2 / \mathrm{N} 2 \\
\mathbf{1 2 4}=\mathbf{P} 2 / \mathbf{N} 1, \mathbf{1 2 5}=\mathbf{P} 2 / \mathrm{N} 1 \\
\mathbf{1 9 2}=\mathbf{P} 2 / \mathbf{N} 1, \mathbf{2 2 8 D E}=\mathbf{N} 2, \\
\mathbf{2 2 9 D E}=\mathbf{N} 2\end{array}$ & $\begin{array}{l}202 \mathrm{FE}=\mathrm{N} 2, \\
204 \mathrm{FE}=\mathrm{N} 2, \\
202 F E=N 2, \\
204 F E=P 2, \\
202 \mathrm{FE}=\mathrm{N} 2, \\
204 \mathrm{FE}=\mathrm{P2}\end{array}$ & - & - \\
\hline $\begin{array}{l}\text { Fan end } \\
\text { bearing faults } \\
12 \mathrm{kHz} \text { data }\end{array}$ & - & $\begin{array}{l}282 \mathrm{FE}=\mathrm{N} 2,285 \mathrm{FE}=\mathrm{N} 2 \\
290 \mathrm{DE}=\mathrm{N} 2,290 \mathrm{FE}=\mathrm{N} 2, \\
292 \mathrm{FE}=\mathrm{N} 2,293 \mathrm{DE}=\mathrm{N} 2 \\
282 \mathrm{FE}=\mathrm{N} 2,285 F E=P 2 \\
290 D E=P 2,290 F E=N 2 \\
292 F E=P 2,293 D E=P 2 \\
282 \mathrm{FE}=\mathrm{N} 2, \mathbf{2 8 5 F E}=\mathbf{P} 2 \\
290 \mathrm{DE}=\mathbf{P} 2,290 \mathrm{FE}=\mathrm{N} 2 \\
\mathbf{2 9 2 F E}=\mathbf{P} 2, \mathbf{2 9 3 D E}=\mathbf{P} 2\end{array}$ & - & $\begin{array}{l}298 \mathrm{BA}=\mathrm{N} 2 \\
298 B A=N 2 \\
\mathbf{2 9 8 B A}=\mathbf{N} 2\end{array}$ & $\begin{array}{l}302=\mathrm{N} 2 / \mathrm{N} 2 / \mathrm{N} 2, \\
305 \mathrm{FE}=\mathrm{N} 2, \\
306=\mathrm{N} 2 / \mathrm{N} 2 / \mathrm{N} 2, \\
307=\mathrm{N} 1 / \mathrm{N} 1 / \mathrm{N} 2, \\
302=\mathrm{N} 2 / \mathrm{N} 2 / \mathrm{N} 2, \\
305 F E=\mathrm{N} 1, \\
306=\mathrm{N} 1 / \mathrm{N} 1 / \mathrm{N} 2, \\
307=\mathrm{N} 1 / \mathrm{P} 2 / \mathrm{N} 2, \\
302=\mathrm{N} 2 / \mathrm{N} 2 / \mathrm{N} 2, \\
\mathbf{3 0 5 F E}=\mathrm{N} 1, \\
306=\mathbf{N} 1 / \mathrm{N} 1 / \mathrm{N} 2, \\
307=\mathbf{N} 1 / \mathrm{P} 2 / \mathrm{N} 2\end{array}$ \\
\hline
\end{tabular}

Figure 7 presents the envelope spectrum estimated from the best-categorized records. Performing SSK, the inner-race (IR) fault remained N1, as shown in Figure 7d, and the ball 
and outer-race (OR) faults were categorized as P1, as failure harmonics were not dominant, as shown in Figure 7e,f. SE was the only approach that presented a Y2 record in OR (see Figure 7c), where failure frequency was dominant. Meanwhile, the IR in Figure 7a and Ball in Figure $7 \mathrm{~b}$ were P2/P1 due to the fault frequency not being dominant. SSE presented smoother PSD (see Figure $7 \mathrm{~h}$ ) in comparison with that of SE (see Figure 7b), but categorization remained the same. Record 197BA was the only downgraded one from Y2 for SE (see Figure 7c) to P1 for SSE (see Figure 7i). This exception can be justified because either approach (SK or SE) did not benefit from the short-time version at constantspeed data.

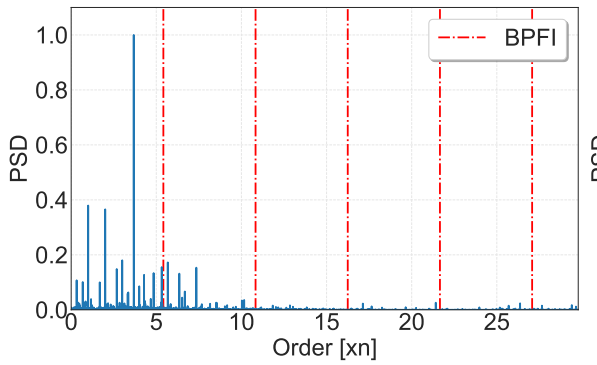

(a) P2-3001DE

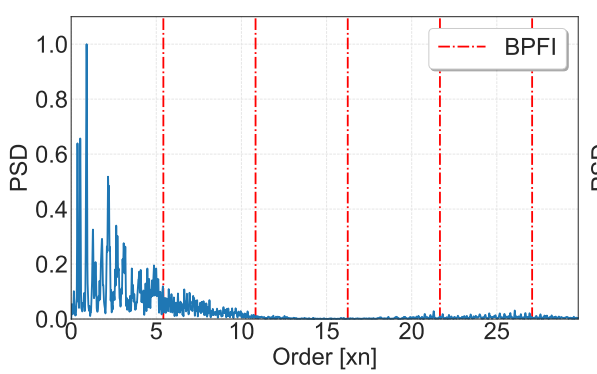

(d) N1-174DE

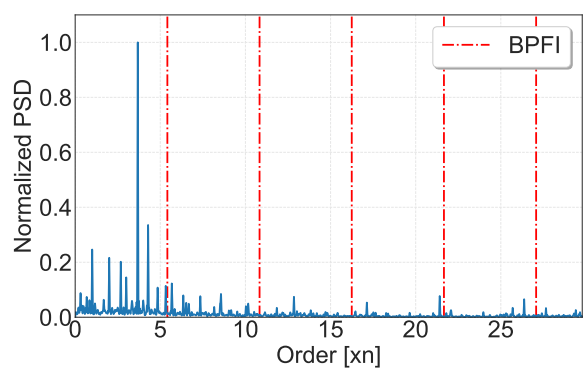

(g) P2-3001DE

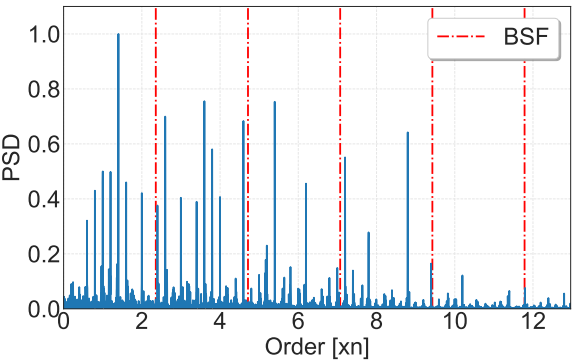

(b) P1-119DE

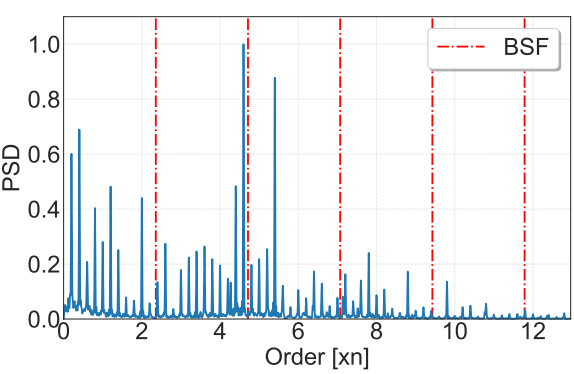

(e) P1-120DE

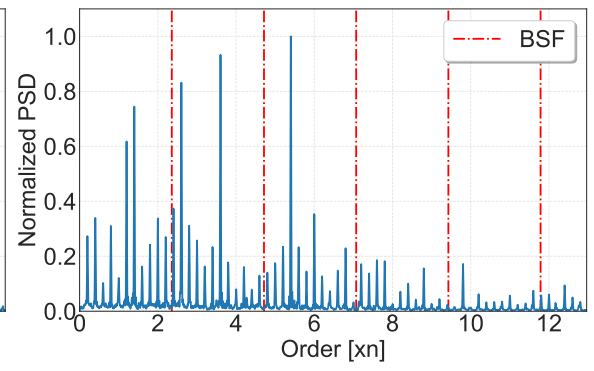

(h) P1-120DE

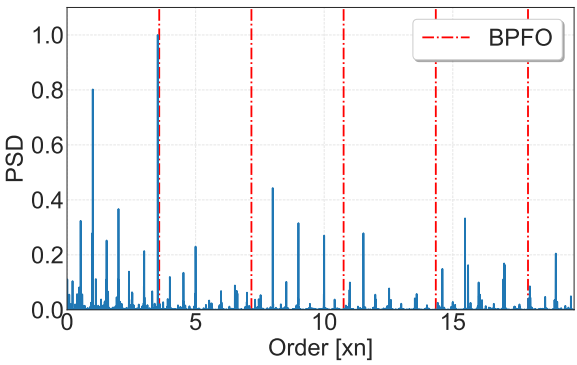

(c) Y2-197BA

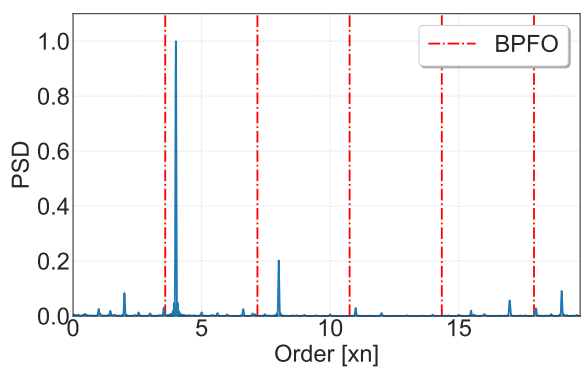

(f) P1-197BA

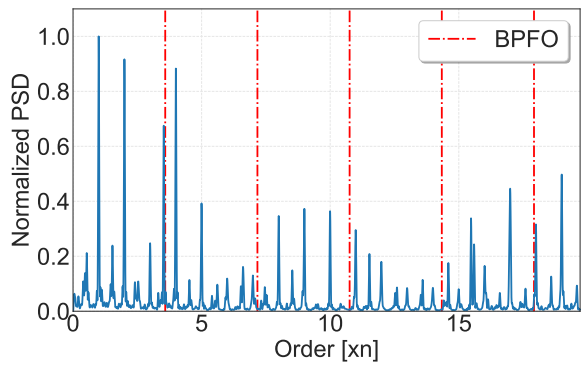

(i) P1-197BA

Figure 7. Assigned labels after visual inspection of envelope spectra (obtained from PSD) estimated by sliding spectral kurtosis (SSK, top row), spectral entropy (SE, middle row), and sliding spectral entropy (SSE, bottom row). One example record is displayed for each considered failure: Left column (inner race (IR)), middle column (ball), and right column (outer race $(\mathrm{OR}))$.

Along with the qualitative diagnosis above discussed in Table 6, we also quantified the impact of short-term feature extraction through the corresponding classifier performance, which was estimated using the CWRU dataset with five-class labeled records. Table 7 presents the accuracy estimates and the advantage of short-time feature strategy in either estimator (SK or SE). State-of-the-art approaches removed the engine influence as an additional procedure. In our case, engine influence was not removed, resulting in more heterogeneous classes. Furthermore, the proposed approach preserved the physical interpretation, allowing for visual inspection and automatic failure detection analysis. 
Additionally, our approach is useful in variable-speed failure detection, as shown in Section 4.1.

Because of the unbalanced trial set, Figure 8 also shows the confusion matrix performed by each contrasted feature-extraction approach, making evident that the class of DE ball reached the highest misclassification values since it held the most considerable number of records.

Table 7. Training classifier accuracy of each filtering approach in Case Western Reserve University (CWRU) dataset compared with several recently reported state-of-the-art works.

\begin{tabular}{lccccccc}
\hline & [33] & [34] & [35] & SK & SSK & SE & SSE \\
\hline Without removing engine influence & - & - & - & $\checkmark$ & $\checkmark$ & $\checkmark$ & $\checkmark$ \\
\hline Visual inspection & - & - & - & $\checkmark$ & $\checkmark$ & $\checkmark$ & $\checkmark$ \\
\hline Accuracy & $\mathbf{9 8 . 9 5}$ & $\mathbf{9 9 . 8 3}$ & 90.46 & $87.64 \pm 2.26$ & $90.24 \pm 2.31$ & $87.27 \pm 2.95$ & $\mathbf{9 4 . 5 3} \pm \mathbf{2 . 2 6}$ \\
\hline
\end{tabular}

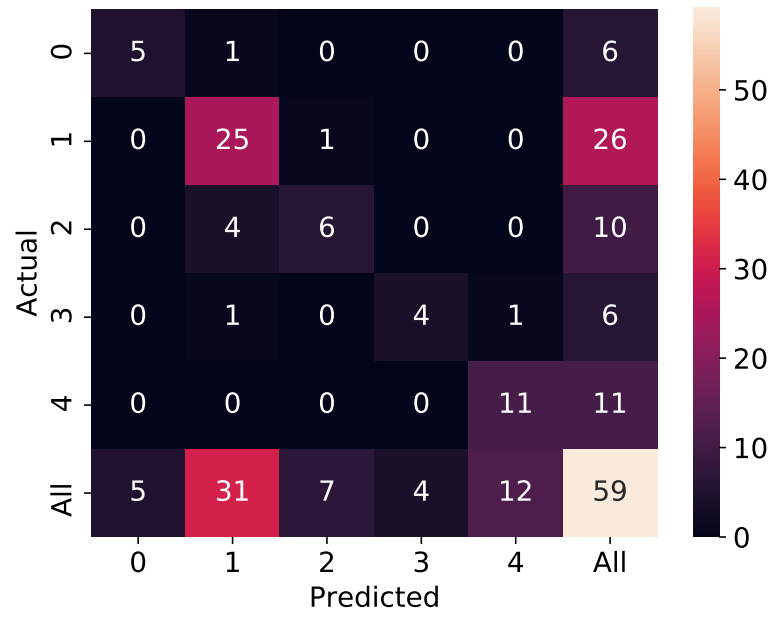

(a) SK

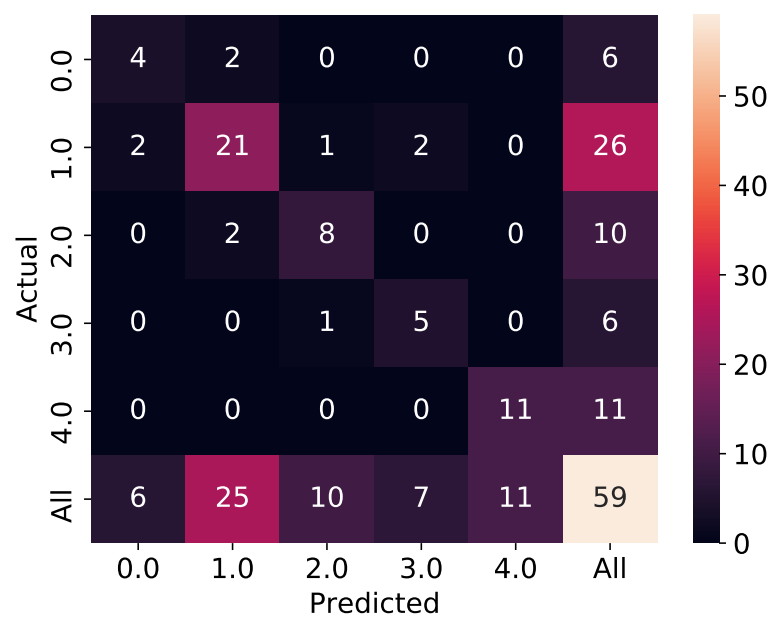

(c) SE

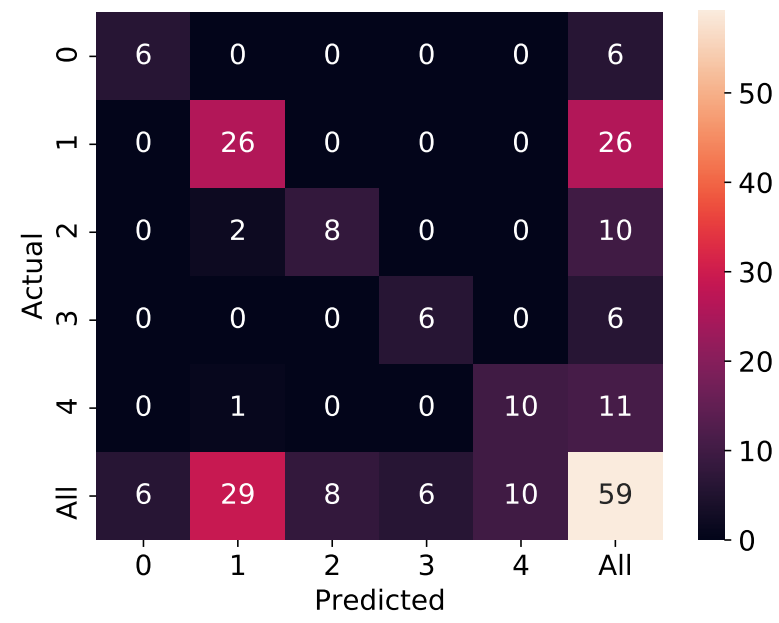

(b) SSK

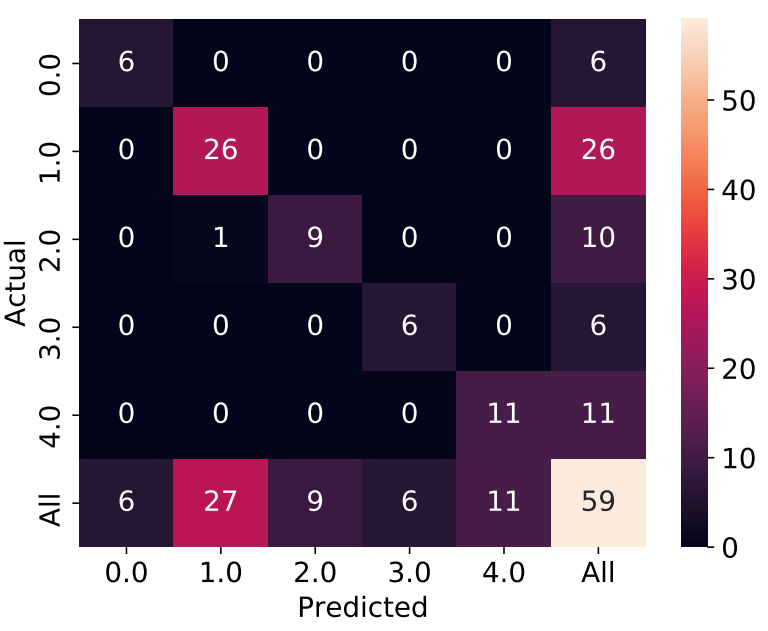

(d) SSE

Figure 8. Confusion matrix of classification stage in CWRU dataset using SK, SSK, SE, and SSE.

\subsection{Experiment Results from UNC}

The test rig (see Figure 9) consisted of a shaft driven by a 1.5 HP DC electric motor able to reach $1720 \mathrm{rpm}$ through the equipped rigid coupling. The test rig had two HTH-UC206 
bearings with two drilling wheels to simulate bearing and unbalanced faults. The dataset held 42 vibration records lasting $4 \mathrm{~s}$ at a sampling rate of $25.6 \mathrm{kHz}$ and variable speed (coast-down). Vibration records were collected in the horizontal plane, employing several accelerometers mounted on bearing supports. The following failures were considered (14 records per failure): inner race (IR), outer race (OR), and ball elements. Damage is was simulated on the bearing located at the shaft end, introducing a crack on the surface of interest with a motor tool. The considered bearing failures had failure frequencies of 5.4783 for BPFI, 3.5217 for BPFO, 2.1913 for BSF, and 0.3913 for the fundamental train frequency (FTF).

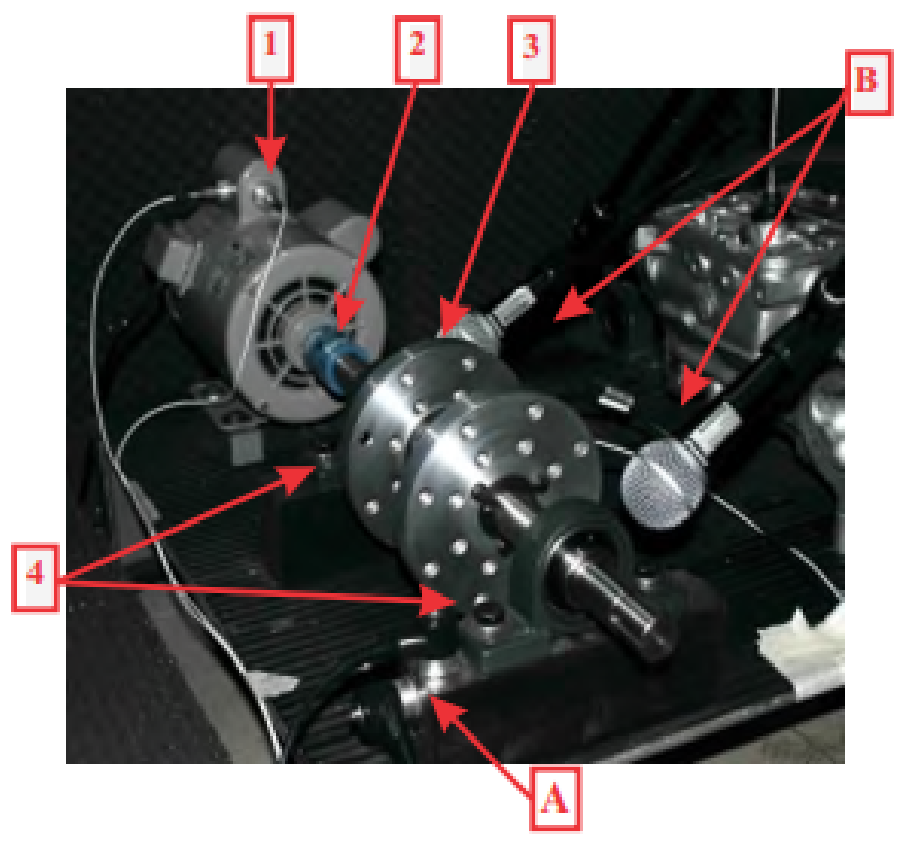

(a)
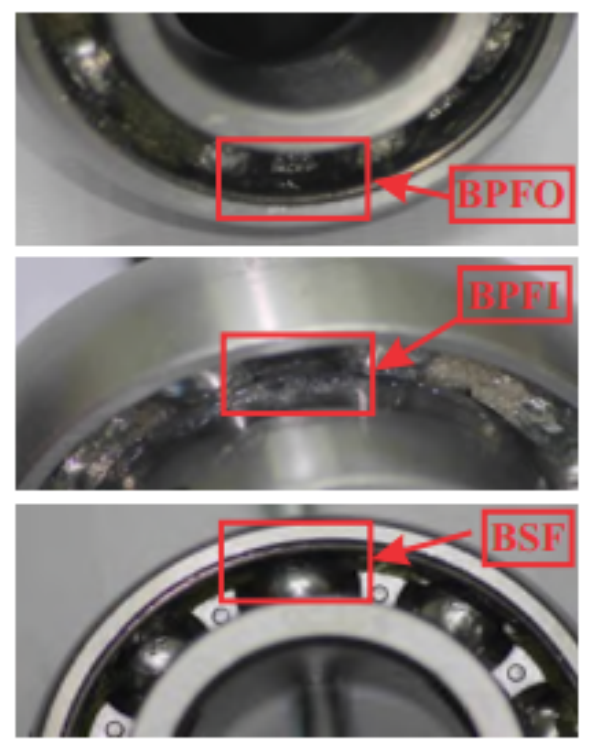

(b)

Figure 9. Experimental test rig (left): (1) motor driven; (2) rigid coupling; (3) drilling wheels; (4) bearing housing. sensor location: (a) accelerometers; and (b) microphones. Simulated OR, IR, and ball defects (right).

Figure 10a displays the spectrogram of a record with IR for which the time-varying signal is presented on the top plot. Because the dataset had no tachometer record, the speed profile was computed using the approach developed in [36], resulting in confident estimates for all OR records. However, the 8 signals' speed profile (6, ball records; 2, IR) was hardly interpretable mainly because of their low signal-to-noise ratio.

For illustration purposes, the vibration record was downsampled (by 32 times) to delineate the speed profile (see Figure 10b). This profile remained similar across the tested record datasets. The spectrogram in Figure 10c shows that IAS influence was excluded by transforming it into the angular domain.

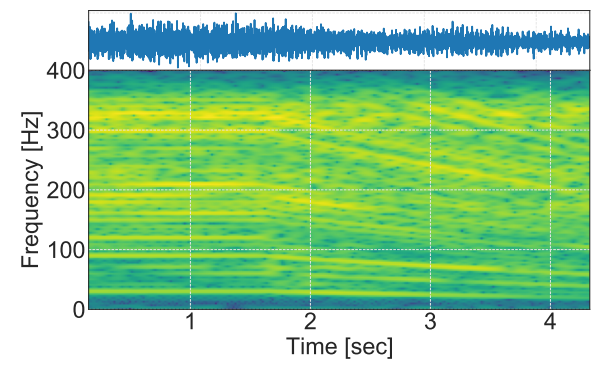

(a) time domain

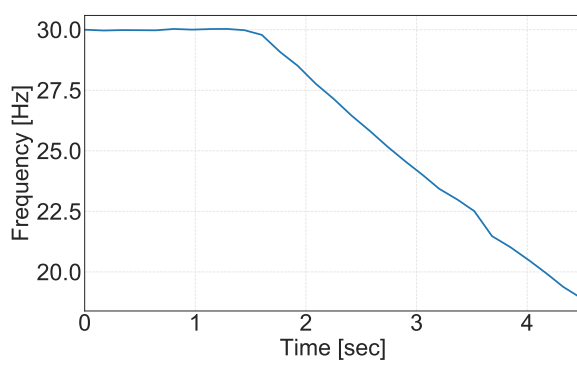

(b) instantaneous angular speed

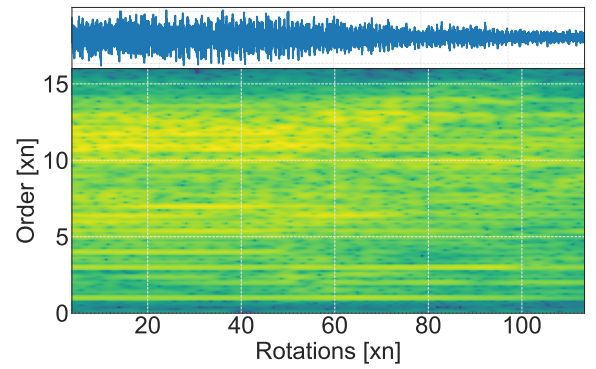

(c) angular domain

Figure 10. Examples of spectrograms estimated for a single IR fault record. 
Figure 11 shows the resulting envelope spectrum computed for each considered filtering scenario. Although BPFI fault frequency appeared after applying each filtering approach, fault frequencies were more visible and dominant in the spectrum performed by SK and SSK (see Figure 11a,g. In BPFO, fault frequency was indistinguishable from noise applying each feature-extraction strategy, except in SSK (see Figure 11h), for which the first fault harmonic was dominant. In ball failure, fault frequency and harmonics were clear and contained the most spectral energy regardless of feature extraction. SSE (see Figure 11l) presented an improvement concerning SE (see Figure 11f).

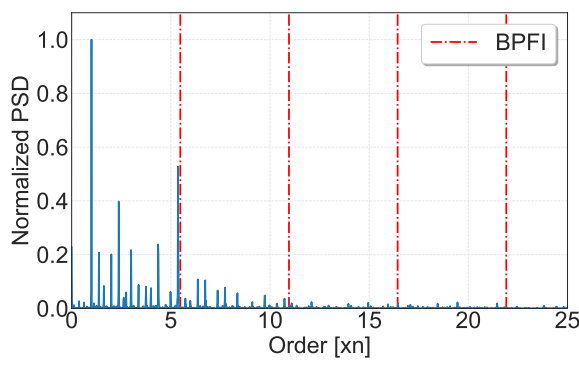

(a)

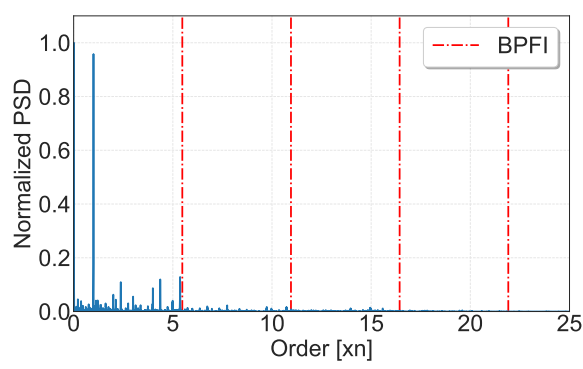

(d)

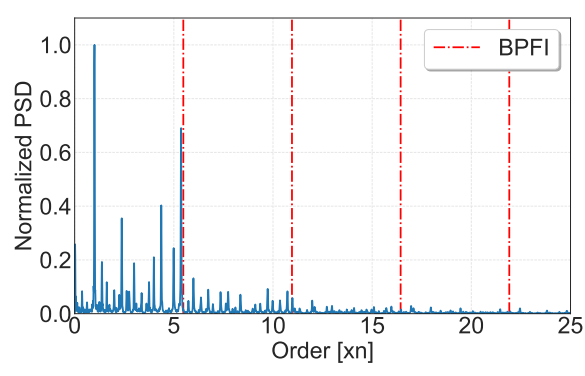

(g)

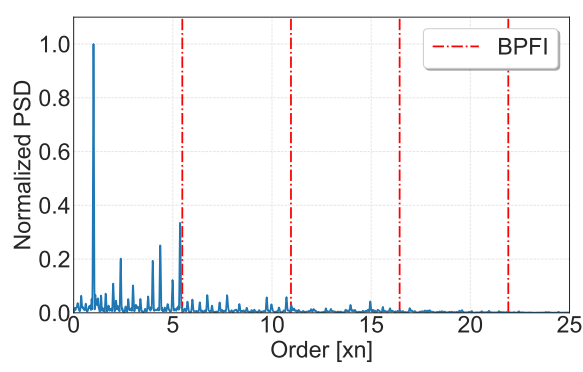

(j)

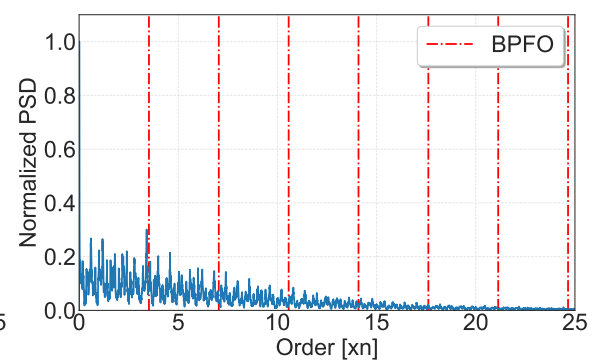

(b)

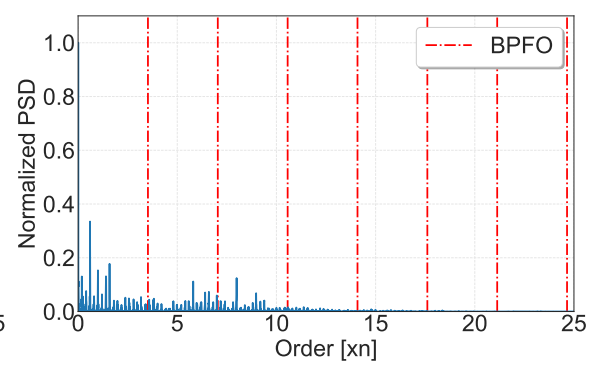

(e)

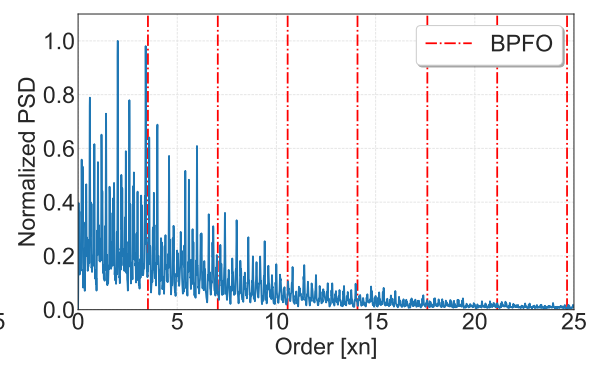

(h)

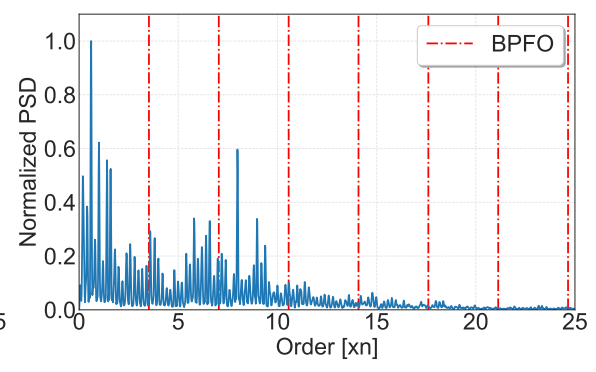

(k)

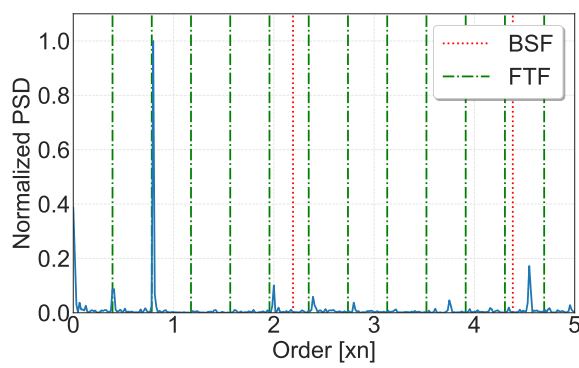

(c)

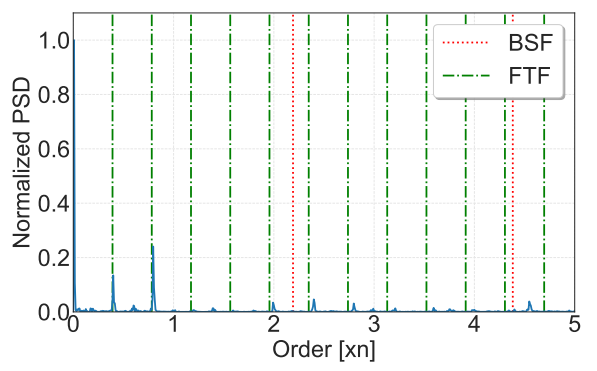

(f)

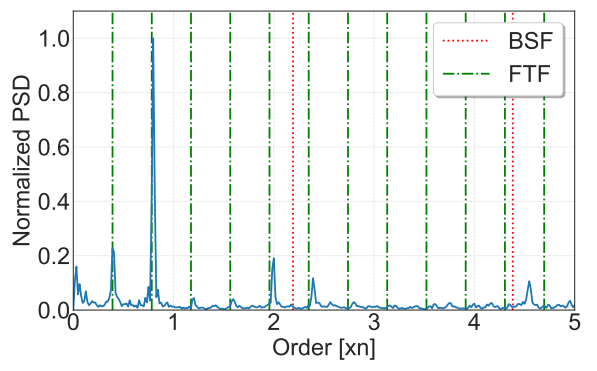

(i)

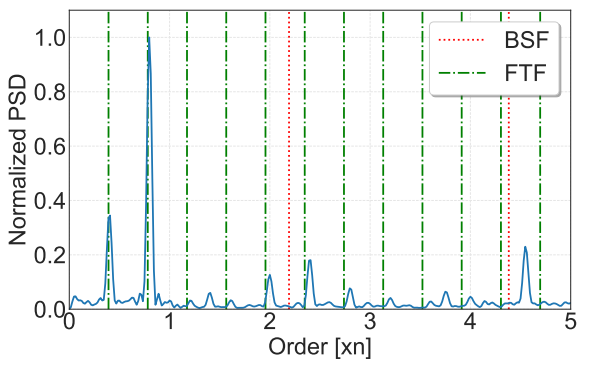

(1)

Figure 11. Envelope-spectrum examples of failures (IR (left column), OR (middle column), and Ball (right column)) computed by SK (top row), SE (second row), SSK (third row), and SSE (fourth row). 
Lastly, we estimated classification performance achieved by the feature extraction approaches using the three-class-labeled information of the following failures (IR, OR, and ball) provided by the UNC database that was imbalanced, as shown in the upper part of Table 8. As a measure of classifier performance, accuracy was initially computed and is depicted in the lower part. Besides, the confusion matrix is shown in Figure 12. Although the four approaches delivered high classification values, SSE had the best outcomes, followed by SE's entropy-based method. Hence, the use of entropy for feature extraction allows for dealing with datasets at variable speeds, resulting in a promising failure indicator.

Table 8. Results of classifier performance. Upper part, Universidad Nacional de Colombia (UNC) dataset used for classifier training, holding assigned class labels, failure types and number of faulty records. Lower part, classification accuracy of each filtering approach.

\begin{tabular}{lcccc}
\hline label & & 0 & 1 & 2 \\
\hline Failure & IR & OR & Ball \\
\hline records & 13 & 14 & 11 \\
\hline & SK & SSK & SE & SSE \\
\hline Accuracy & $99.68 \pm 0.93$ & $98.82 \pm 1.31$ & $99.79 \pm 0.71$ & 100 \\
\hline
\end{tabular}

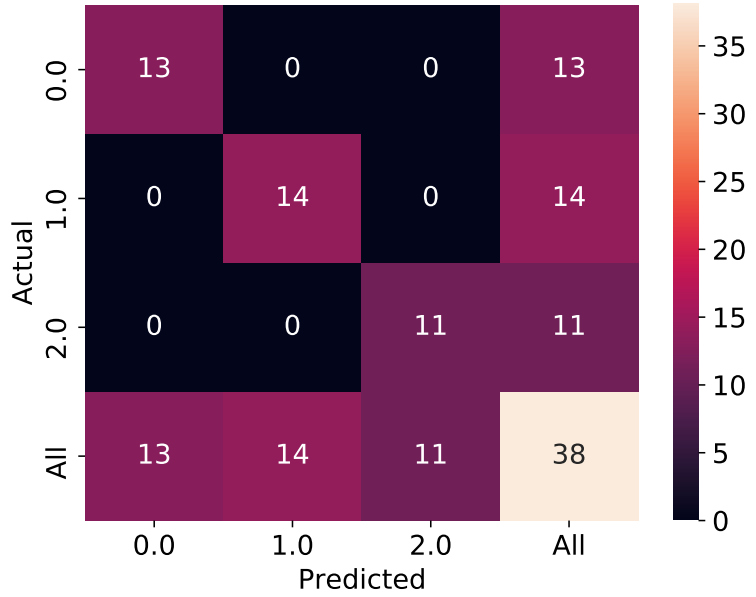

(a) SK

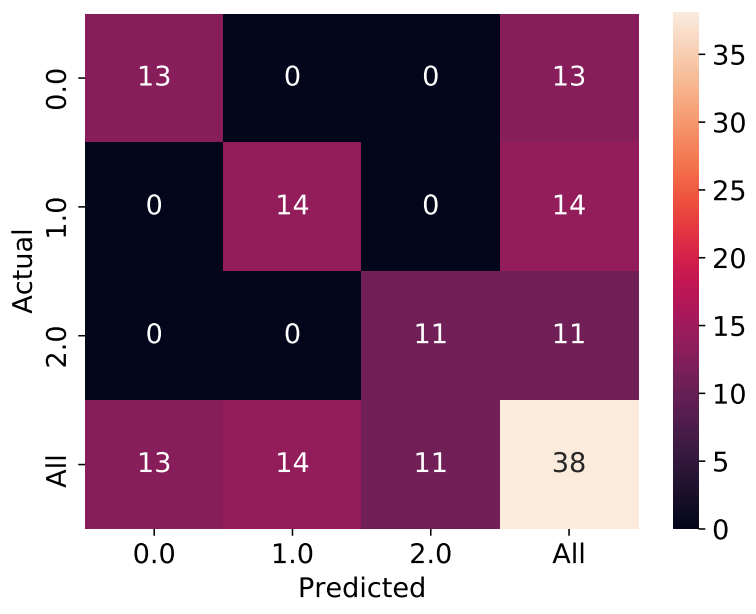

(c) SE

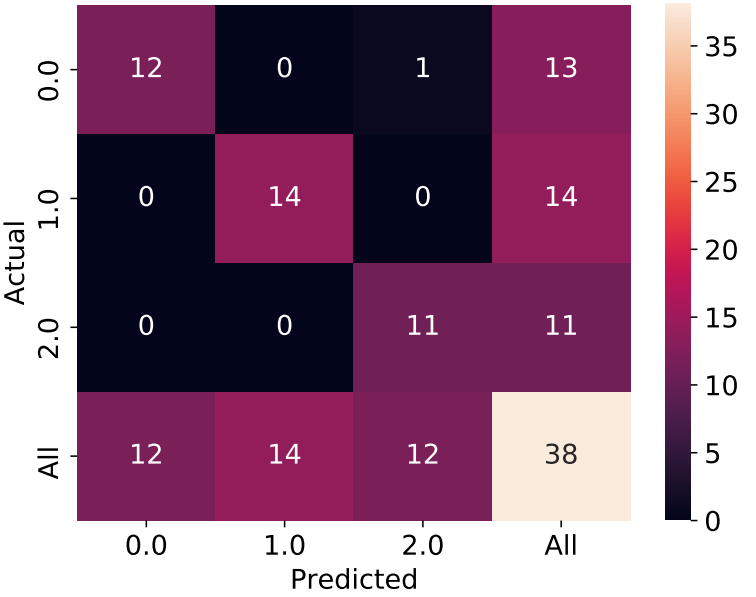

(b) SSK

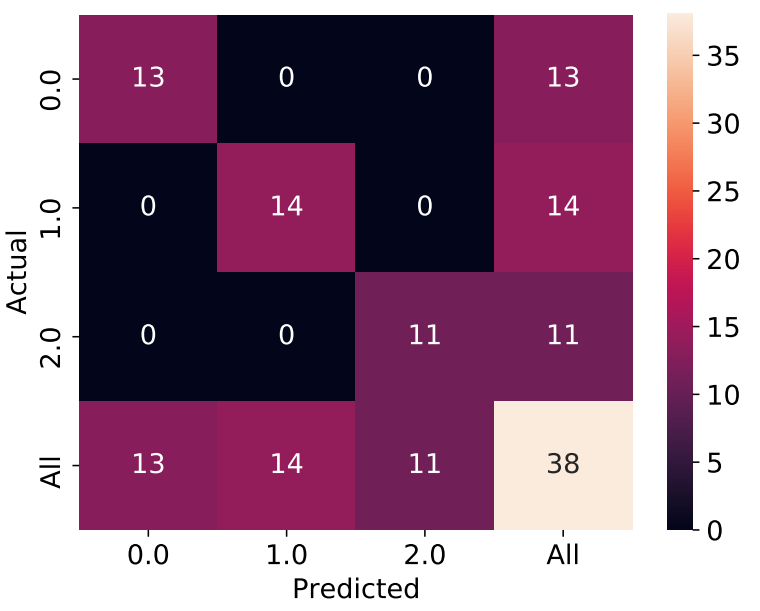

(d) SSE

Figure 12. Confusion matrix of classification stage in UNC dataset, using SK, SSK, SE, and SSE. 


\section{Conclusions}

This paper introduced an approach to identifying impulsive bearing failures from variable-speed vibrations by properly emphasizing corresponding envelope-spectrum components. To this end, we measured short-term spectral components operating a small window for extracting instantaneous amplitudes and a large interval for simultaneously assessing the average background. The emphasizing high-order-based estimator based on the principle of spectral entropy was introduced to characterize the impulsive behavior. Both visual inspection and classifier performance were assessed, contrasting the introduced estimator with the widely used spectral-kurtosis approach for dealing with impulsive signals. The validation of the short-time/-angle spectral analysis, performed on three datasets at variable speed, showed that the proposed spectral-entropy estimator is a promising indicator for emphasizing bearing failures with impulse behavior.

From the obtained validation results, the following were concluded:

Simulation of rolling-element bearing faults. Evaluation is was initially carried out on an artificial framework, allowing for testing all considered ERB and showing that they could be prognosticated. Furthermore, the model could reproduce the results of more elaborate filtering, such as a tested sliding approach like the vanishing spectrum (e.g., $i$-th harmonic being stronger than $i+1$-th).

Evaluation of real-world data. The obtained results from visual inspection in the aircraft-engine data (SAFRAN) showed that each emphasizing spectral filter had poor performance leading to a noisy envelope spectrum regardless of used estimator (SK or SE). As a result, they have limited diagnostic capacity. Instead, the sliding strategy more accurately depicts the envelope spectrum with a dominant presence of the fault frequency and all its harmonics. Hence, the sliding short-term approach, combined with the evaluated emphasizing moment-based estimators, improved the angular domain's failure diagnosis. In the UNC database, visual examination results behaved similarly to previous data, except for outer-race failures that could only be acceptably handled by the SSK approach. Accounting for collecting data simplicity, this issue with OR may be explained by acquiring data difficulties. In fact, the obtained classifier performance was very high despite the failure class. Still, the SSE estimator outperformed other filtering approaches.

Spectral filter using moment-based estimators. Under constant instantaneous angular speed, SE and SK performance was similar to that by their sliding versions, at least in terms of visual inspection for the tested REB failures. However, evaluating vibration data with variable instantaneous angular speed, sliding strategy remarkably enhanced visual examination and classification accuracy. However, some small differences were noted between the performance achieved by each moment-based estimator.

The authors plan to improve spectral-estimation extraction for future work using more effective techniques, such as wavelet transform. However, since vibration data can be converted into 2D representations, such as spectrograms, the authors plan to develop image-based deep-learning models combined with feature-extraction layers, benefiting from the entropy estimator explained above.

Author Contributions: conceptualization, Á.Á.O.G., H.F.Q., and G.C.-D.; methodology, E.F.S.-A., H.F.Q., and G.C.-D.; software, E.F.S.-A.; validation, J.C.-A. and E.F.S.-A.; formal analysis, Á.Á.O.G., H.F.Q., and G.C.-D.; investigation, E.F.S.-A. and J.C.-A.; resources, Á.Á.O.G. and H.F.Q.; data curation, E.F.S.-A.; writing—original-draft preparation, E.F.S.-A., G.C.-D.; writing—review and editing, J.C.-A., Á.Á.O.G. and H.Q; visualization, E.F.S.-A.; supervision, G.C.-D.; project administration, Á.Á.O.G. and H.F.Q.; funding acquisition, Á.Á.O.G. and H.F.Q. All authors have read and agreed to the published version of the manuscript.

Funding: This work was carried out under Convocatoria 647/2014 Colciencias-Colfuturo. This work was also partially supported by Maestría en Ingeniería Eléctricafrom Universidad Tecnológica de Pereira.

Institutional Review Board Statement: Not applicable.

Informed Consent Statement: Not applicable. 
Data Availability Statement: The CWRU dataset is publicly available at https:/ / csegroups.case.edu/ bearingdatacenter/pages/welcome-case-western-reserve-university-bearing-data-center-website; The SAFRAN dataset is publicly available under the instructions at [31]; and the UNC dataset is available upon request to the corresponding author.

Conflicts of Interest: The authors declare that this research was conducted in the absence of any commercial or financial relationships that could be construed as a potential conflict of interest.

\section{References}

1. Nithin, S.; Hemanth, K.; Shamanth, V. A review on combustion and vibration condition monitoring of IC engine. Mater. Today Proc. 2020, in press. [CrossRef]

2. Koukoura, S.; Carroll, J.; McDonald, A. On the use of AI based vibration condition monitoring of wind turbine gearboxes. J. Phys. Conf. Ser. 2019, 1222, 012045. [CrossRef]

3. Strömbergsson, D.; Marklund, P.; Berglund, K.; Larsson, P.E. Bearing monitoring in the wind turbine drivetrain: A comparative study of the FFT and wavelet transforms. Wind. Energy 2020, 23, 1381-1393. [CrossRef]

4. John, S.K.; Mishra, R.; Hari, K.; Ramesha, H.; Ram, K.K. Investigation of Bearing Failure in a Turbo Shaft Engine. J. Fail. Anal. Prev. 2020, 20, 34-39. [CrossRef]

5. He, F.; Xie, G.; Luo, J. Electrical bearing failures in electric vehicles. Friction 2020, 8, 4-28. [CrossRef]

6. Delprete, C.; Brusa, E.; Rosso, C.; Bruzzone, F. Bearing Health Monitoring Based on the Orthogonal Empirical Mode Decomposition. Shock Vib. 2020, 2020, 8761278. [CrossRef]

7. Goyal, D.; Mongia, C.; Sehgal, S. Applications of Digital Signal Processing in Monitoring Machining Processes and Rotary Components: A Review. IEEE Sensors J. 2021, 21, 8780-8804. [CrossRef]

8. He, M.; He, D. A new hybrid deep signal processing approach for bearing fault diagnosis using vibration signals. Neurocomputing 2020, 396, 542-555. [CrossRef]

9. Tao, H.; Wang, P.; Chen, Y.; Stojanovic, V.; Yang, H. An unsupervised fault diagnosis method for rolling bearing using STFT and generative neural networks. J. Frankl. Inst. 2020, 357, 7286-7307. [CrossRef]

10. Hou, B.; Wang, D.; Wang, Y.; Yan, T.; Peng, Z.; Tsui, K.L. Adaptive Weighted Signal Preprocessing Technique for Machine Health Monitoring. IEEE Trans. Instrum. Meas. 2020, 70,1-11. [CrossRef]

11. $\mathrm{Hu}, \mathrm{Y}$; $\mathrm{Li}$, Q. An adjustable envelope based EMD method for rolling bearing fault diagnosis. IOP Conf. Ser. Mater. Sci. Eng. 2021, 1043, 032017. [CrossRef]

12. Attoui, I.; Oudjani, B.; Boutasseta, N.; Fergani, N.; Bouakkaz, M.S.; Bouraiou, A. Novel predictive features using a wrapper model for rolling bearing fault diagnosis based on vibration signal analysis. Int. J. Adv. Manuf. Technol. 2020, 106, 3409-3435. [CrossRef]

13. Wang, H.; Du, W. Feature extraction of latent fault components of rolling bearing based on self-learned sparse atomics and frequency band entropy. J. Vib. Control. 2020, 27. [CrossRef]

14. Peeters, C.; Antoni, J.; Helsen, J. Blind filters based on envelope spectrum sparsity indicators for bearing and gear vibration-based condition monitoring. Mech. Syst. Signal Process. 2020, 138, 106556. [CrossRef]

15. Jia, X.; Zhao, M.; Di, Y.; Li, P.; Lee, J. Sparse filtering with the generalized lp/lq norm and its applications to the condition monitoring of rotating machinery. Mech. Syst. Signal Process. 2018, 102, 198-213. [CrossRef]

16. He, L.; Yi, C.; Wang, D.; Wang, F.; Lin, J.H. Optimized minimum generalized Lp/Lq deconvolution for recovering repetitive impacts from a vibration mixture. Measurement 2021, 168, 108329. [CrossRef]

17. Chen, W.; Li, J.; Wang, Q.; Han, K. Fault feature extraction and diagnosis of rolling bearings based on wavelet thresholding denoising with CEEMDAN energy entropy and PSO-LSSVM. Measurement 2021, 172, 108901. [CrossRef]

18. Yang, C.; Jia, M. Hierarchical multiscale permutation entropy-based feature extraction and fuzzy support tensor machine with pinball loss for bearing fault identification. Mech. Syst. Signal Process. 2021, 149, 107182. [CrossRef]

19. Wang, Z.; Yao, L.; Cai, Y. Rolling bearing fault diagnosis using generalized refined composite multiscale sample entropy and optimized support vector machine. Measurement 2020, 156, 107574. [CrossRef]

20. Minhas, A.S.; Kankar, P.; Kumar, N.; Singh, S. Bearing fault detection and recognition methodology based on weighted multiscale entropy approach. Mech. Syst. Signal Process. 2021, 147, 107073. [CrossRef]

21. Kumar, A.; Gandhi, C.; Zhou, Y.; Kumar, R.; Xiang, J. Variational mode decomposition based symmetric single valued neutrosophic cross entropy measure for the identification of bearing defects in a centrifugal pump. Appl. Acoust. 2020, 165, 107294. [CrossRef]

22. Huo, Z.; Zhang, Y.; Jombo, G.; Shu, L. Adaptive multiscale weighted permutation entropy for rolling bearing fault diagnosis. IEEE Access 2020, 8, 87529-87540. [CrossRef]

23. Song, J.; Shi, Z.; Wang, L.; Wang, H. Random error analysis of MEMS gyroscope based on an improved DAVAR algorithm. Micromachines 2018, 9, 373. [CrossRef]

24. Jiang, L.; Gao, B.; Gu, J.; Chen, Y.; Gao, Z.; Ma, X.; Kendrick, K.M.; Woo, W.L. Wearable long-term social sensing for mental wellbeing. IEEE Sensors J. 2018, 19, 8532-8542. [CrossRef]

25. Shukla, S.; Singh, S.K.; Mitra, D. An efficient heart sound segmentation approach using kurtosis and zero frequency filter features. Biomed. Signal Process. Control. 2020, 57, 101762. [CrossRef] 
26. Serrano Calle, S. Measuring Uncertainties in Energy Companies Caused by Governmental Regulation: The Role of Information Theory. USAEE Work. Pap. 2012, 12, 148. [CrossRef]

27. Antoni, J. Cyclic spectral analysis in practice. Mech. Syst. Signal Process. 2007, 21, 597-630. [CrossRef]

28. Velasquez-Martinez, L.; Caicedo-Acosta, J.; Castellanos-Dominguez, G. Entropy-Based Estimation of Event-Related De/Synchronization in Motor Imagery Using Vector-Quantized Patterns. Entropy 2020, 22, 703. [CrossRef] [PubMed]

29. Antoni, J. The spectral kurtosis: A useful tool for characterising non-stationary signals. Mech. Syst. Signal Process. 2006, 20, 282-307. [CrossRef]

30. Randall, R.B.; Antoni, J.; Chobsaard, S. The relationship between spectral correlation and envelope analysis in the diagnostics of bearing faults and other cyclostationary machine signals. Mech. Syst. Signal Process. 2001, 15, 945-962. [CrossRef]

31. Antoni, J.; Griffaton, J.; André, H.; Avendaño-Valencia, L.D.; Bonnardot, F.; Cardona-Morales, O.; Castellanos-Dominguez, G.; Daga, A.P.; Leclère, Q.; Vicuña, C.M.; et al. Feedback on the Surveillance 8 challenge: Vibration-based diagnosis of a Safran aircraft engine. Mech. Syst. Signal Process. 2017, 97, 112-144. [CrossRef]

32. Smith, W.A.; Randall, R.B. Rolling element bearing diagnostics using the Case Western Reserve University data: A benchmark study. Mech. Syst. Signal Process. 2015, 64, 100-131. [CrossRef]

33. Marins, M.A.; Ribeiro, F.M.; Netto, S.L.; da Silva, E.A. Improved similarity-based modeling for the classification of rotatingmachine failures. J. Frankl. Inst. 2018, 355, 1913-1930. [CrossRef]

34. Li, Y.; Wang, X.; Si, S.; Huang, S. Entropy based fault classification using the Case Western Reserve University data: A benchmark study. IEEE Trans. Reliab. 2019, 69, 754-767. [CrossRef]

35. Sun, S.; Przystupa, K.; Wei, M.; Yu, H.; Ye, Z.; Kochan, O. Fast bearing fault diagnosis of rolling element using Lévy Moth-Flame optimization algorithm and Naive Bayes. Eksploat. Niezawodn. Maint. Reliab. 2020, 22, 730-740. [CrossRef]

36. Sierra-Alonso, E.F.; Antoni, J.; Castellanos-Dominguez, G. Cyclo-non-stationary analysis for bearing fault identification based on instantaneous angular speed estimation. In Proceedings of the Surveillance, Vishno and AVE Conferences, Lyon, France, 8-10 July 2019. 